Archive for

Organic Chemistry

Arkivoc 2018, part iv, 23-49

\title{
Use of nitrogen and oxygen dipole ylides for alkaloid synthesis
}

\author{
Albert Padwa \\ Department of Chemistry, Emory University, Atlanta, Ga 30322 \\ Email: chemap@emory.edu
}

Dedicated to Gordon Gribble on the occasion of his

50th year retirement from Dartmouth College

Received 11-29-2017

Accepted 01-06-2018

Published on line 02-06-2018

\section{Abstract}

As highlighted in this mini review, a growing area of interest in organic synthesis involves the use of substituted azomethine and carbonyl ylides as 1,3-dipoles for the preparation of alkaloidal natural products. Cascade reactions proceeding by an intramolecular 1,3-dipolar cycloaddition of nitrogen and oxygen dipole ylides are of particular interest to the synthetic organic community because of the increase in molecular complexity involved and the high isolated yields.

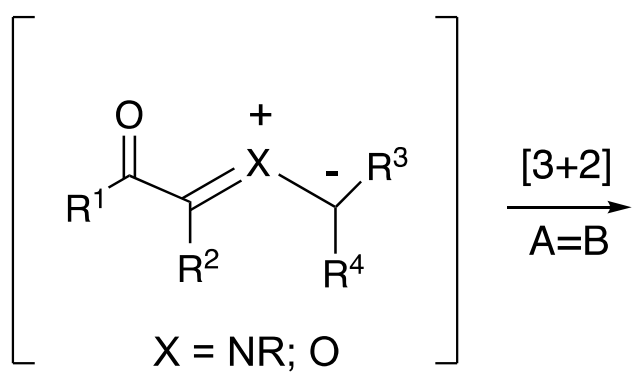

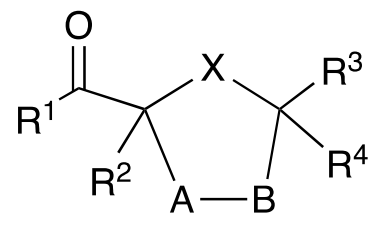

Various alkaloids

Keywords: 1,3-Dipole, azomethine ylide, carbonyl ylide, intramolecular, dipolar cycloaddition, alkaloid synthesis 


\section{Table of Contents}

1. Introduction

2. Azomethine Ylides

2.1 Dipolar cycloaddition using stabilized azomethine ylides from amino acids

2.2 Azomethine ylide generation using an iminium ion desilylation protocol

3. Alkaloid target synthesis

3.1 ( \pm )-Indolizidine 239CD

3.2 ( \pm )-Demethoxyschelammericine

3.3 Amaryllidaceae alkaloids

3.4 Daphnane alkaloids

4. Carbonyl Ylides

4.1 Rh(II)-catalyzed reaction of diazo carbonyl substrates for ylide generation

5. Alkaloid Target Synthesis

5.1 ( \pm )-Aspidophytine

5.2 Kopsifoline skeleton

5.3 Vinca and tacaman alkaloids

5.4 (-)-Vindoline

6. Conclusions

7. Acknowledgements

8. References

\section{Introduction}

1,3-Dipolar cycloaddition reactions are among the most powerful methods in organic synthesis. ${ }^{1} \mathrm{~A}$ particularly attractive feature is their ability to rapidly increase molecular complexity and lead to a high degree of functionality. These unique reactions were extensively studied by the Huisgen group starting in the early 1960s and their rate and regioselectivity can be understood through FMO analysis. ${ }^{2-4}$ [3+2]-Cycloadditions are also extremely useful for the synthesis of natural products such as alkaloids and other biologically important structures employing rather simple starting materials. In addition, dipolar cycloadditions using chiral substrates for enantioselective synthesis has been extensively explored since the 1990s. ${ }^{5}$ Because several reviews and related articles have recently been published dealing with the synthetic aspects of dipolar cycloaddition chemistry for the preparation of natural products, 6,7 this mini-review for Gordon Gribble's upcoming $50^{\text {th }}$ year retirement is intended to provide a selective rather than an exhaustive survey of the use of both azomethine and carbonyl ylide dipoles for alkaloid synthesis.

\section{Azomethine Ylides}

\subsection{Dipolar cycloaddition using stabilized azomethine ylides from amino acids}

Azomethine ylides have emerged as one of the more useful 1,3-dipoles for the synthesis of a variety of alkaloids. 8 Several methods have been employed to generate azomethine ylides for use in dipolar cycloaddition chemistry. ${ }^{3}$ A particularly common method is the condensation of $\mathrm{N}$-alkyl amino acid derivatives with aldehydes 
followed by decarboxylation to afford the 1,3-dipole. The Coldham group employed this method in their approach toward the synthesis of a variety of alkaloids. In a formal synthesis of deethylibophylidine, for example, heating a toluene solution of aldehyde 1 and $N$-allyl glycine (2) at reflux produced 3 in $42 \%$ yield (Scheme 1). ${ }^{9}$ The $N$-allyl group was subsequently removed to furnish 4 in $40 \%$ yield, which represents an intermediate in the synthesis of deethylibophyllidine.

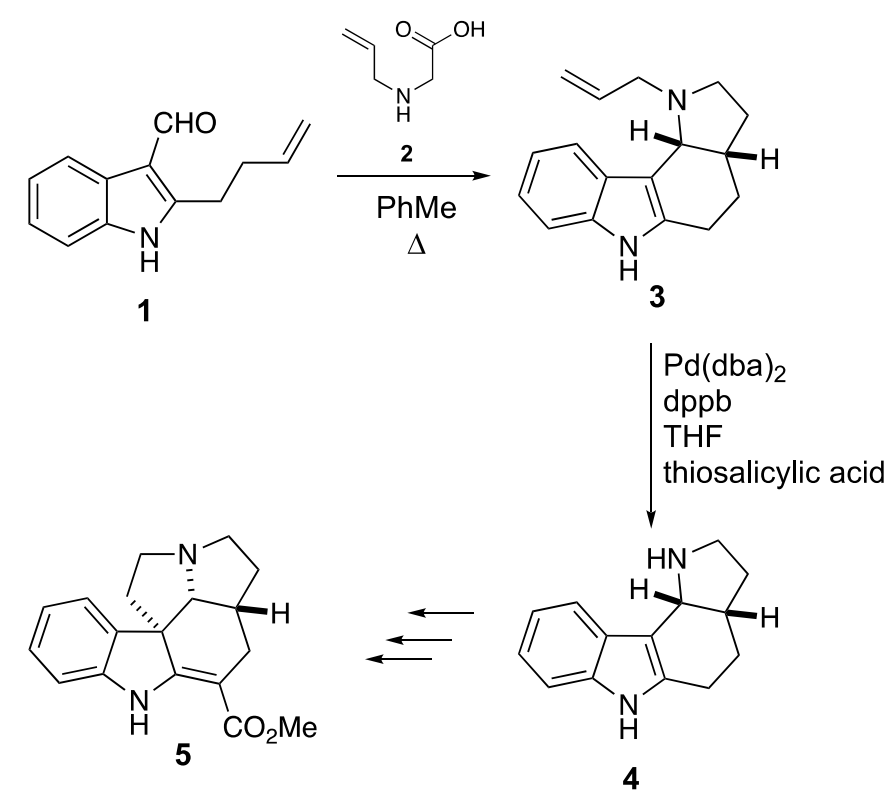

\section{Scheme 1}

Lovely et al. used a [3+2]-cycloaddition reaction as the key step in an approach to martinellic acid $13 .{ }^{10}$ In this synthesis, the reaction of aldehyde 6 with benzyl glycine 7 produced $65 \%$ of 8 which was subsequently reduced to afford tricyclic alcohol $\mathbf{9}$ in $88 \%$ yield (Scheme 2). Compound $\mathbf{9}$ was then converted in several steps to afford triamine 10. Finally, a $\mathrm{AgNO}_{3}$ mediated guanylation of 10 with 11 gave 12 in $62 \%$ yield. This constitutes a formal synthesis of martinellic acid $\mathbf{1 3}$, as the hydrolysis of the ester was previously reported.

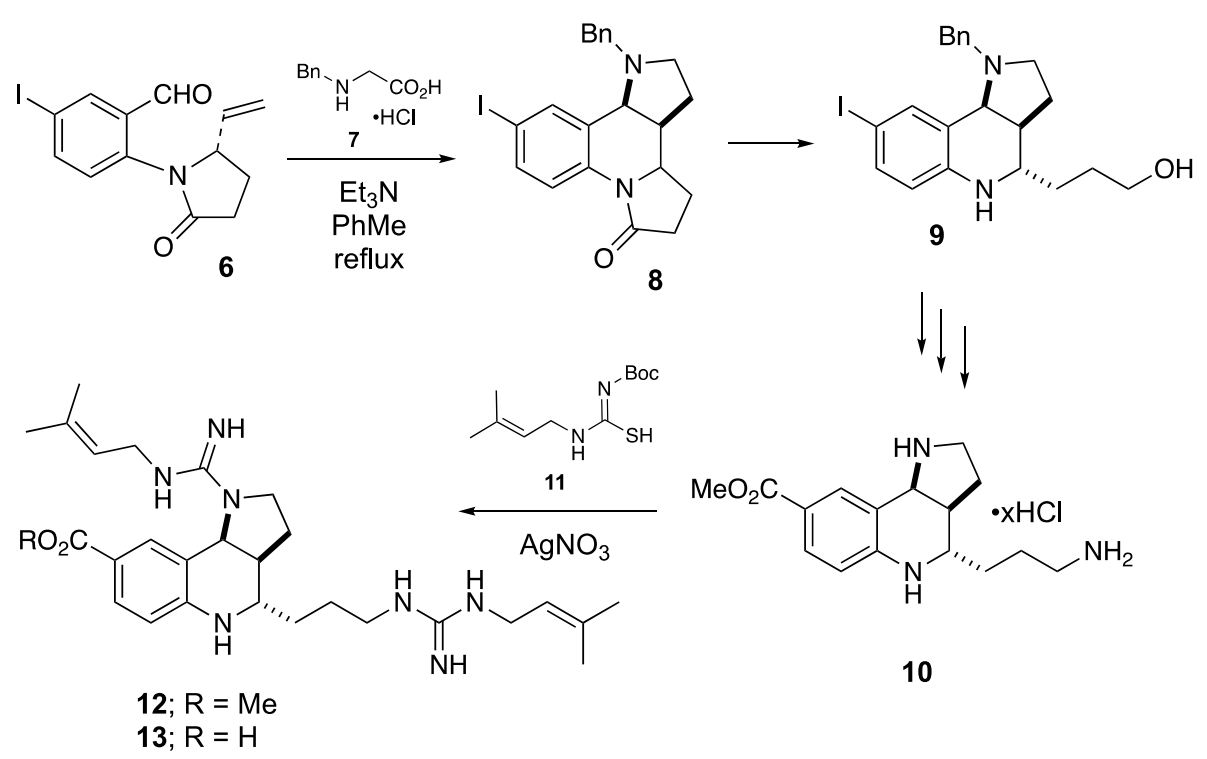


Stabilized azomethine ylides can easily be formed using amino acids and their esters to generate an imine that is subsequently alkylated to generate an iminium ion. Decarboxylation or deprotonation then affords the reactive azomethine ylide. Coldham and coworkers examined the scope of this type of "condensation alkylation - cycloaddition" cascade wherein the acid-catalyzed condensation of 14a with glycine ethyl ester $\mathbf{1 5}$ followed by intramolecular cyclization generated azomethine ylide 16a. This 1,3-dipole then cycloadded across the pendant olefin to give 17 a in $81 \%$ yield as a single diastereomer (Scheme 3). ${ }^{11}$ Likewise, 14b,c produced $\mathbf{1 7 b}, \mathbf{c}$ in $72 \%$ and $51 \%$ yield, respectively. Alternatively, 14d underwent the cascade sequence to produce 18 in $74 \%$ yield. Presumably, the increased conformational flexibility in this system allows a transition state that gives rise the trans-fused product. Application of this cascade to the synthesis of natural products began with the exposure of $\mathbf{1 9}$ to glycine, giving amine $\mathbf{2 0}$ in 79\% yield. Hydrolysis of the ketal group delivered ketone $\mathbf{2 1}$ in $\mathbf{8 9 \%}$ yield, which was subsequently converted into aspidospermidine $\mathbf{2 2}$ and several other aspidospermine alkaloids through Fischer indole syntheses.

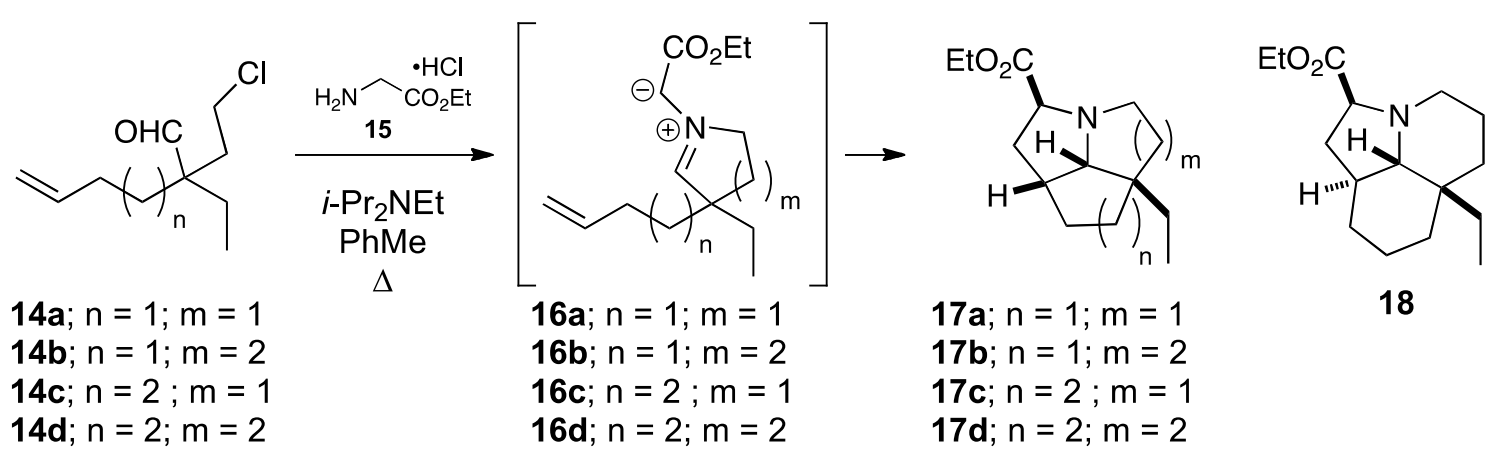

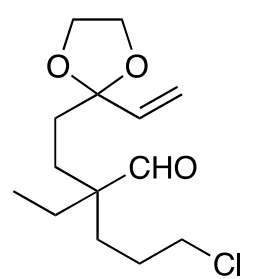

19

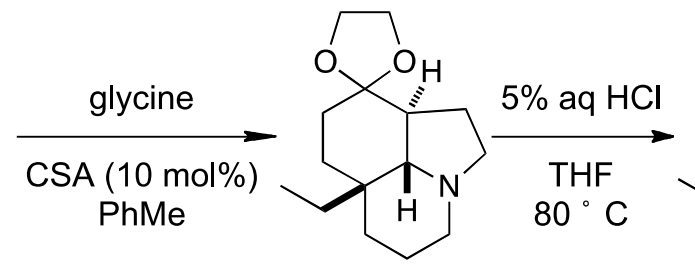

20

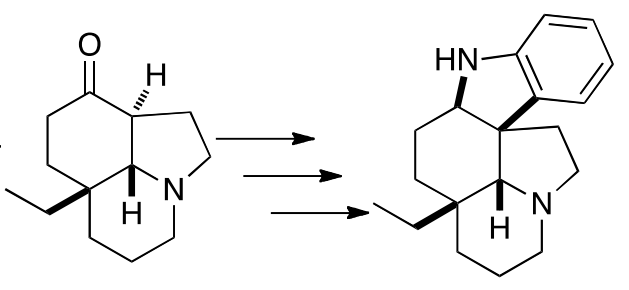

21

22

\section{Scheme 3}

Another example employing a carbonyl stabilized azomethine ylide for alkaloid synthesis was reported by Banwell in 1997.12 The pivotal step in his approach to the lamellarin class of alkaloids involved the deprotonation of an iminium ion to generate the dipole. Construction of the central pyrrole moiety of the alkaloid proceeded via an intramolecular [3+2]-cycloaddition of an isoquinoline-based azomethine ylide dipole to a suitably tethered alkyne (Scheme 4). Thus, ester 23 was first reacted with 3,4-dihydro-6,7-dimethoxy-5isopropoxyisoquinoline to give salt 24. Treatment of $\mathbf{2 4}$ with Hunig's base followed by air oxidation of the resulting cycloadduct afforded compound $\mathbf{2 5}$ which was subsequently converted to lamellarin K 26 in $96 \%$ yield. 
<smiles>CCCOc1cc(OC)c(OCC)cc1C#Cc1ccc(OCC)c(OC)c1</smiles><smiles>COc1cc2c(c(OC)c1OC)CCN=C2</smiles><smiles>COc1cc(-c2c3n(c4c(=O)oc5cc(O)c(O)cc5c24)CCc2c-3cc(OC)c(OC)c2O)ccc1O</smiles>

26, lammellarin $\mathrm{K}$

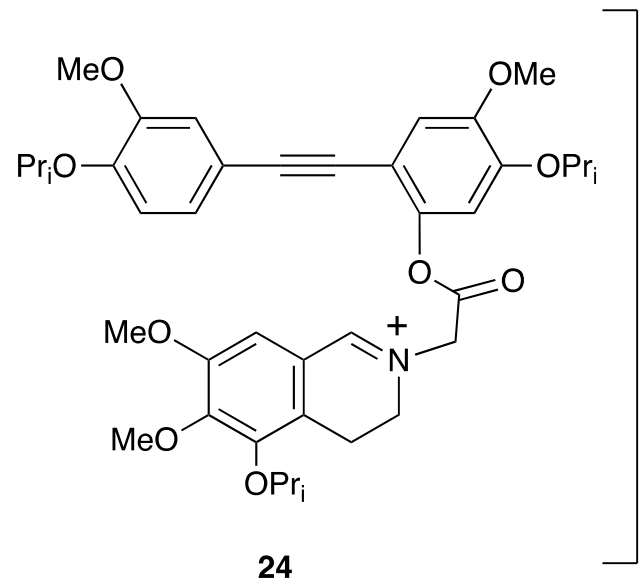

$\mid \begin{aligned} & \text { Hünig's } \\ & \text { base }\end{aligned}$<smiles>CCCOc1cc2oc(=O)c3c(c(-c4ccc(OC)c(OC)c4)c4n3CCc3c-4cc(OC)c(OC)c3OC(C)C)c2cc1OC</smiles>

25

\section{Scheme 4}

In an early communication by the Coldham group in 1999, they disclosed that the key step in an approach to the manzamine alkaloids proceeded by an intramolecular azomethine ylide cycloaddition of a carbonyl stabilized dipole. ${ }^{13}$ This reaction forms rings $B$ and $C$ simultaneously, together with three new chiral centers and allowed a rapid access to the core $A B C$ ring system of manzamine $A$. Thus, condensation of the secondary amine sarcosine ethyl ester $\mathbf{2 8}$ with aldehyde $\mathbf{2 7}$ resulted in the formation of azomethine ylide $\mathbf{2 9}$ (Scheme 5). Intramolecular cycloaddition resulted in the generation of the pyrrolidine ring $C$, together with simultaneous formation of ring $B$. A single diastereomeric product $\mathbf{3 0}$ was obtained which consisted of the desired $A B C$ ring system of the manzamine alkaloids.

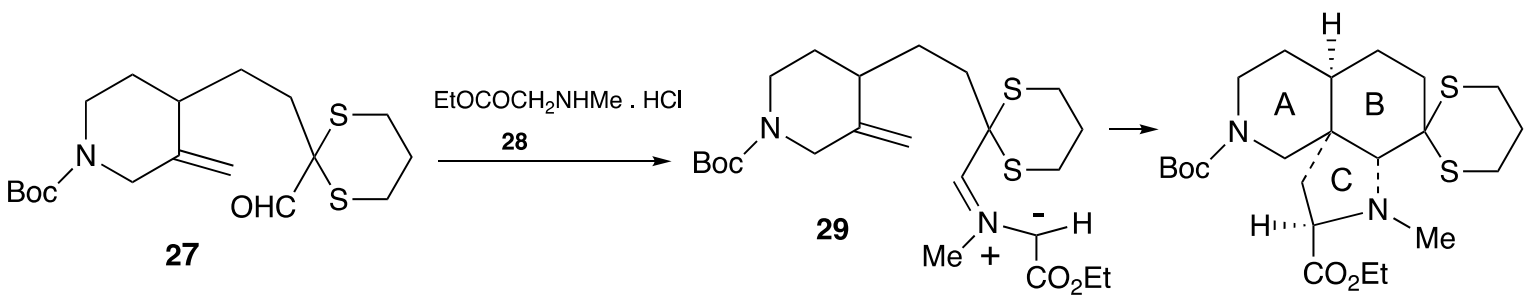

\section{Scheme 5}


In a follow up report, this same intramolecular azomethine ylide cycloaddition protocol was used by Coldham in conjugation with a ring closing metathesis to prepare the tetracyclic ABCE ring system of manzanine A 34. ${ }^{14}$ Addition of $\mathrm{N}$-allyl glycine ethyl ester to aldehyde $\mathbf{3 1}$ afforded the tricyclic compound $\mathbf{3 2}$ as the major diastereomer (Scheme 6). This compound was subsequently converted to compound $\mathbf{3 3}$ in five subsequent steps. The ring-closing metathesis was carried out in $75 \%$ yield thereby providing the critical tetracyclic $A B C E$ ring system of manzamine $\mathrm{A} 34$.

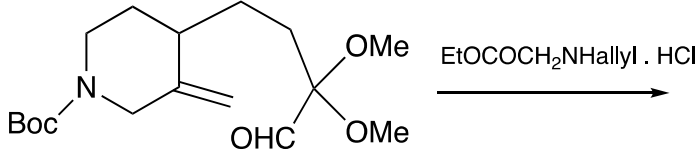

31

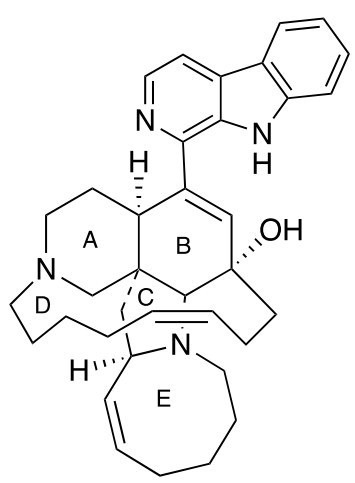

34; manzanine A<smiles>C=CCN1C2C(OC)(OC)CC[C@H]3CCN(C(=O)OC(C)(C)C)C[C@@]23C[C@H]1C(=O)OC</smiles>

32

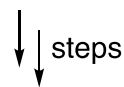<smiles>C=CCCCC(=O)N1[C@H](C=C)C[C@]23CN(C(=O)OC(C)(C)C)CC[C@H]2CCC(OC)(OC)[C@H]13</smiles>

33

\section{Scheme 6}

In 2017, Banwell and coworkers reported a biomimetic total synthesis of the pentacyclic Amaryllidaceae alkaloid derivative gracilamine 37.15 Azomethine ylide 35, produced via a Schiff base condensation of the corresponding aldehyde containing C3a-arylhexahydroindole with ethyl L-leucinate, engages in a stereoselective intramolecular dipolar cycloaddition reaction to give adduct $\mathbf{3 6}$ (Scheme 7). This compound was further elaborated, over eight steps, into the racemic modification of the alkaloid derivative gracilamine 37 . The formation of azomethine ylide $\mathbf{3 5}$ and its conversion into compound $\mathbf{3 6}$ mimics the proposed biogenesis of the pentacyclic framework of gracilamine $\mathbf{3 7}$.

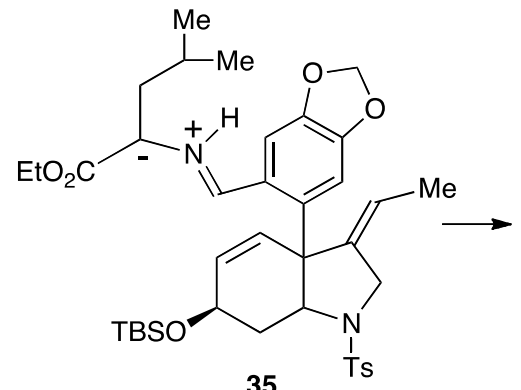

35

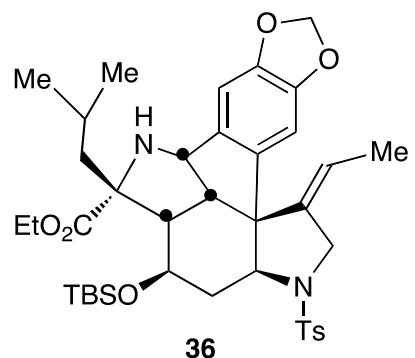

36

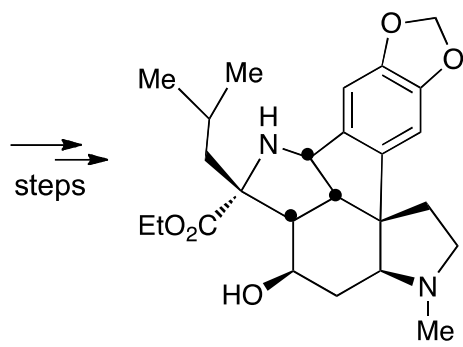

37; gracilamine

\section{Scheme 7}


In an approach to the stemofoline class of alkaloids, the Martin group discovered an unusual set of conditions for generating azomethine ylides. Oxidation of compound $\mathbf{3 8}$ under Swern conditions afforded a 5:1 mixture of $\mathbf{4 1}$ and $\mathbf{4 2}$ in 69\% yield (Scheme 8). ${ }^{16}$ The formation of these two molecules can be easily rationalized via an intramolecular 1,3-dipolar cycloaddition of dipole 40, but the mechanism through which the azomethine ylide is formed under Swern conditions is not well understood. The authors proposed that the oxidized product 39a derived from 38 reacted with one of the electrophilic species formed under the reaction conditions to give 39b. A subsequent loss of a proton as well as the leaving $X$ group would then produce dipole $\mathbf{4 0 .}$

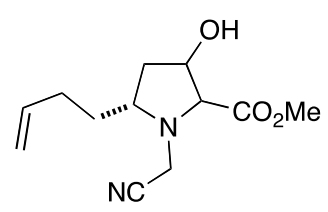

38

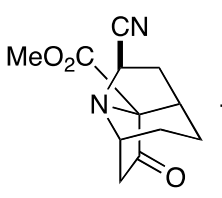

41
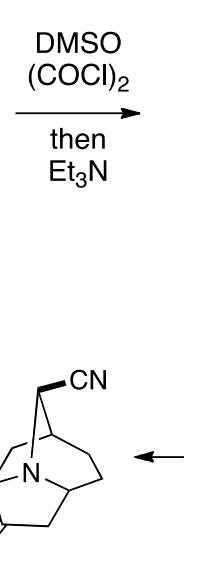

42

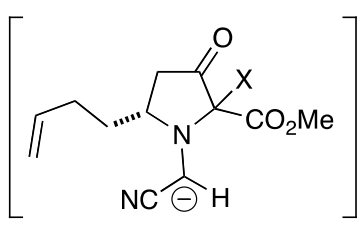

39a; $\mathrm{X}=\mathrm{H}$

39b; $\mathrm{X}=\mathrm{Cl}, \mathrm{SMe}_{2}$

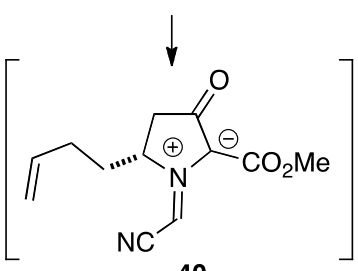

40

\section{Scheme 8}

Even with considerable experimentation, the inability to easily remove the cyano group in structures $\mathbf{4 1}$ and $\mathbf{4 2}$ necessitated an alternate route to the key azomethine ylide intermediate. Ultimately, Martin and coworkers settled on the intramolecular reaction of the imino group in compound $\mathbf{4 3}$ with the critical carbenoid intermediate being obtained by a rhodium(II)-catalyzed decomposition of the diazo group in $\mathbf{4 3}$ so as to provide dipole 44 (Scheme 9). ${ }^{17}$ Subsequent cycloaddition of the resulting azomethine ylide with the tethered alkene afforded 45 in $75 \%$ yield. Tricycle 45 was subsequently transformed into (+)-46, an intermediate used by Overman in a synthesis of $( \pm)$ - didehydrostemofoline and isodidehydrostemofoline. ${ }^{18}$

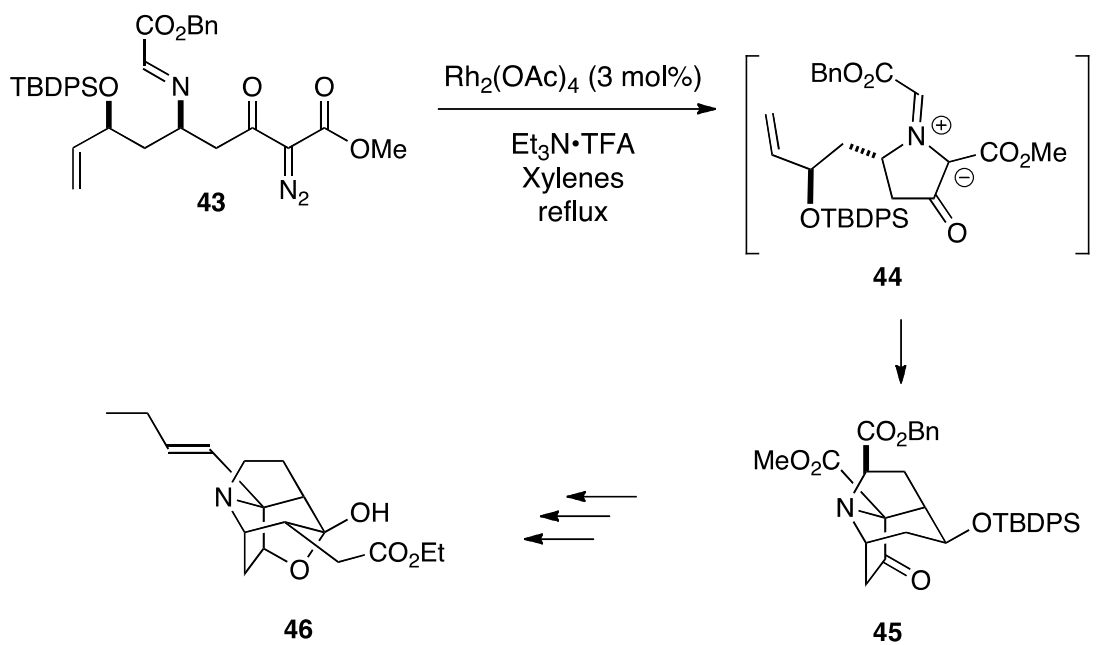

\section{Scheme 9}




\subsection{Azomethine ylide generation using an iminium ion desilylation protocol}

In 1984 the 1,3-dipolar cycloaddition of azomethine ylides derived by a desilylation reaction attracted our attention as a particularly appealing approach for pyrrolidine synthesis. We found that the desilylation of $N$ (trimethylsilyl)methylamino ethers was a very convenient method for azomethine ylide generation. ${ }^{19-21}$ Treatment of compounds of type $\mathbf{4 7}$ with LiF in the presence of a reactive dipolarophile afforded dipolar cycloadducts in high yield. The overall cycloaddition reaction presumably proceeds by the initial generation of an iminum ion from $\mathbf{4 7}$ which then is followed by desilylation to produce dipole $\mathbf{4 8}$. Trapping dipole $\mathbf{4 8}$ with a variety of dipolarophiles afforded products of type $\mathbf{4 9}$ in high yield. Our interest in the enantioselective synthesis of substituted pyrrolidine derivatives by this process also led us to study the [3+2]-cycloaddition of chiral azomethine ylides. The dipole precursors were prepared from enantiomerically pure R-methylbenzylamines, and the diastereoselectivity of the [3+2]-cycloaddition was studied in some detail (Scheme 10).

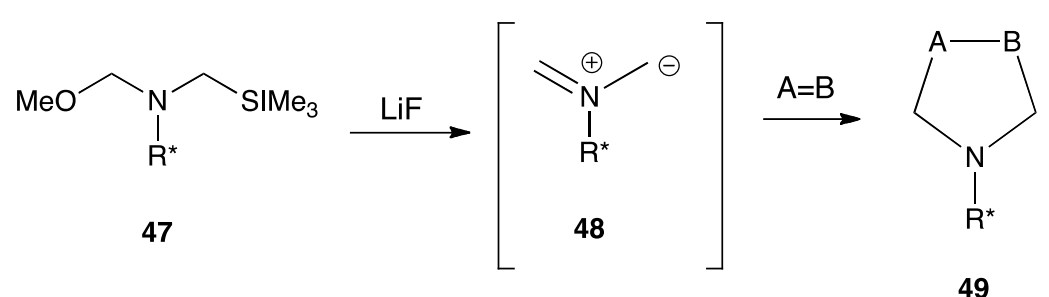

\section{Scheme 10}

\section{Alkaloid target synthesis}

\section{1. ( \pm )-Indolizidine 239CD}

Livinghouse and coworkers used this iminium ion desilylation protocol to generate the skeleton framework of the erythrinan family of alkaloids. ${ }^{22}$ Alkylation of dihydroisoquinoline $\mathbf{5 0}$ with trimethylsilylmethyl triflate gave the iminium ion 51, which was then desilylated with cesium fluoride to form azomethine ylide $\mathbf{5 2}$ (Scheme 11). An intramolecular cycloaddition between the ylide and the terminal acetylenic dipolarophile of $\mathbf{5 2}$ resulted in the formation of azatetracycle $\mathbf{5 3}$ that contains the core of the erythrinane scaffold.

Another related method for the generation and cycloaddition of nonstabilized $N$-unsubstituted azomethine ylides involves the treatment of (2-azaally)stannanes $\mathbf{5 6}$ with HF-pyridine by a process involving $\mathrm{N}$-protonation and destannylation. 23,24 Compared to other methods for azomethine ylide formation, notable features of this route include the tolerance for aliphatic groups, good trans 2,5-diasteroselectivity in the pyrrolidine product, and mild reaction conditions. An early application of this method toward alkaloids was carried out by the Pearson group and involved its use in the synthesis of (+/-)indolizidine 239CD 60, one of several natural occurring indolizidines that possess a trans 2,5-disubstituted pyrrolidine in their structure. ${ }^{24}$ Thus hydrazinolysis of phthalimide $\mathbf{5 4}$ gave the expected amine which was condensed with aldehyde $\mathbf{5 5}$ under typical imine formation conditions to produce the (2-azallyl)stannane 56 (Scheme 12). This imine was then treated with phenyl vinyl sulfone and the mixture was allowed to react with HF-pyridine to provide pyrrolidine $\mathbf{5 8}$ via ylide $\mathbf{5 7}$ as a mixture of diastereomers. Removal of the ketal group and intramolecular reductive amination created compound $\mathbf{5 9}$ which was subsequently converted into the desired alkaloid $\mathbf{6 0}$. 

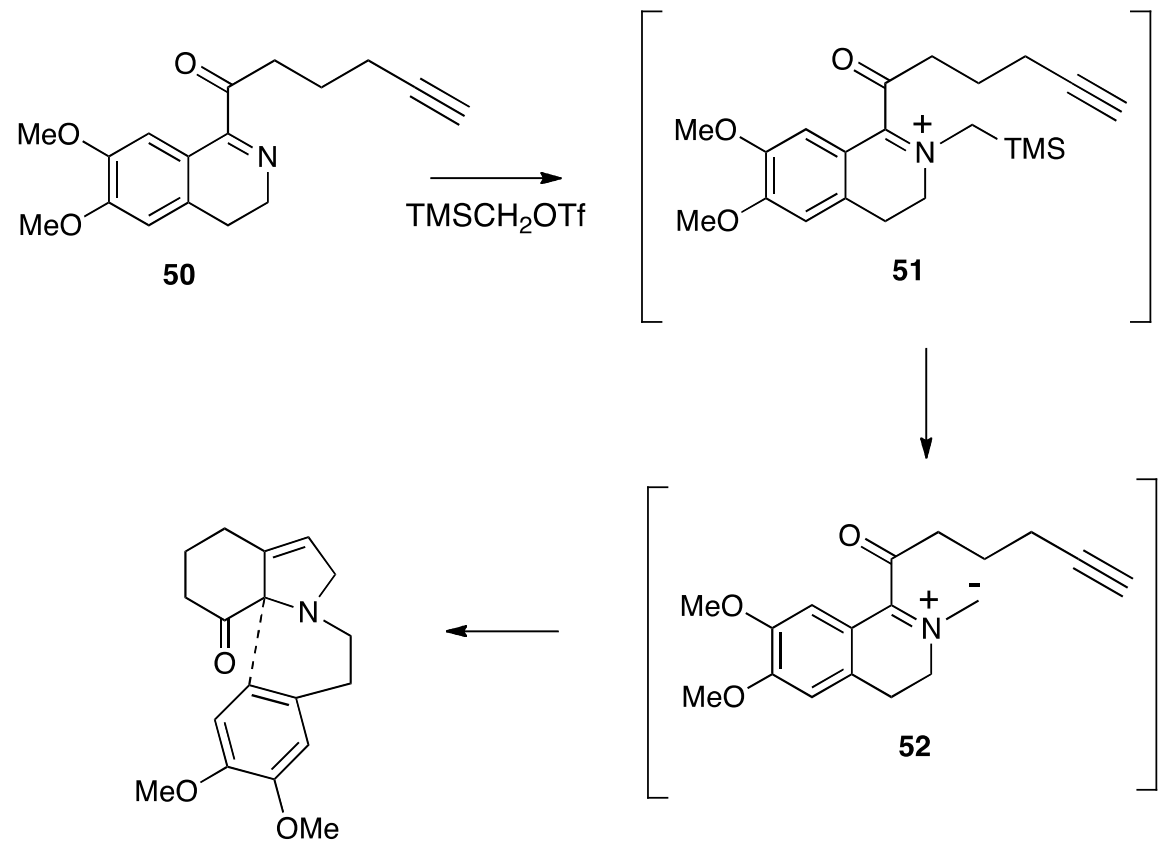

53

\section{Scheme 11}

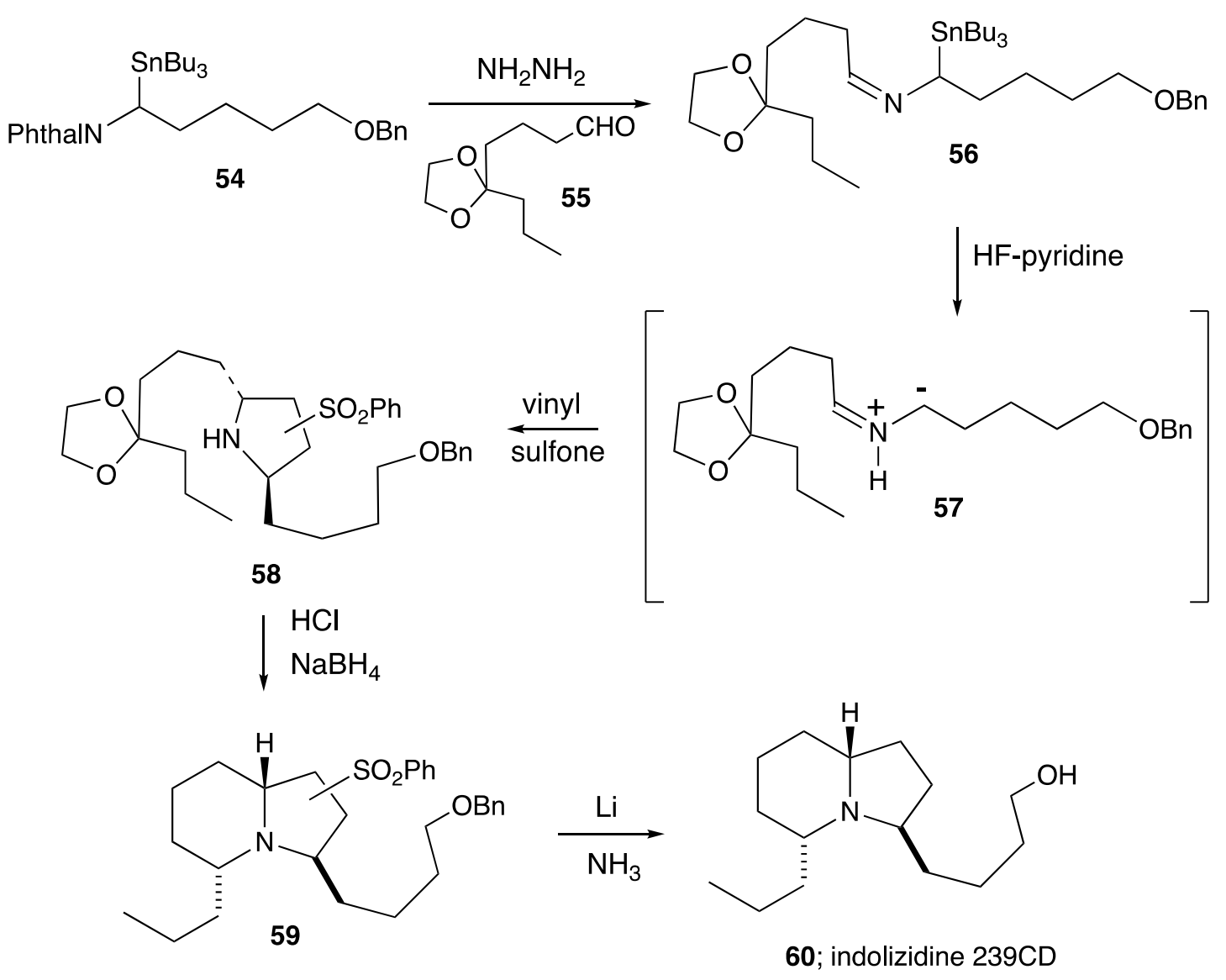

Scheme 12 


\section{2. ( \pm )-Demethoxyschelammericine}

In a later publication Pearson described his efforts toward the total synthesis of the homoerythrina class of alkaloids including the preparation of demethoxyschelhammericine 64.25 The key feature of this syntheses involves the successful formation of the A-C rings of the alkaloid using a tandem $\mathrm{N}$-alkylation/azomethine ylide [3+2] cycloaddition (Scheme 13). This critical step features both an intramolecular $\mathrm{N}$-alkylation of a tethered electrophile and an intramolecular cycloaddition of a tethered dipolarophile.

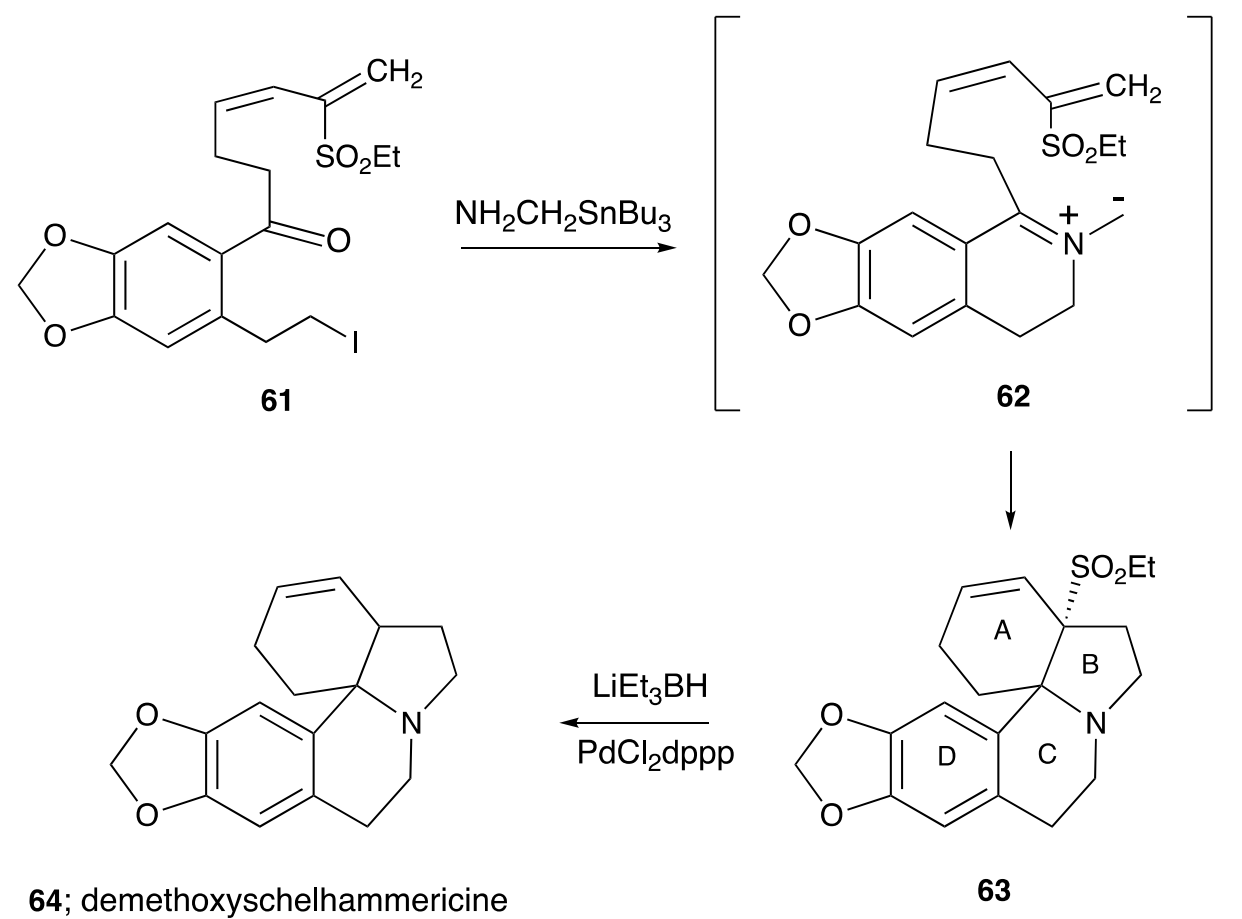

\section{Scheme 13}

The condensation of secondary $\mathrm{N}$-(trimethylsilyl)methyl amines with carbonyl compounds has also been shown to be an effective method to generate unstabilized azomethine ylides upon desilylation. For example, the $A C D$ azatricylic 69 , which represents the core of the calyciphylline type $A$ daphniphyllum alkaloid $\mathbf{7 0}$, was formed in $55 \%$ yield by mixing 65 and amine 66 in DMF at rt in the presence of catalytic amounts of $\mathrm{H}_{3} \mathrm{PO}_{4}$ (Scheme 14). ${ }^{26}$ In this cascade sequence, condensation of the amine with aldehyde 65 produced iminium ion 67. Cleavage of the silyl group then gave azomethine ylide $\mathbf{6 8}$ that underwent cycloaddition across the pendant electron-deficient alkene to produce 69.

There are also several examples of imidate derived azomethine ylides reported in the literature. For example, the Gin group described a clever use of these 1,3-dipoles in an approach to the azatricyclic core of some stemofoline members of the stemona alkaloid family. The formation of the azomethine ylide $\mathbf{7 2}$ occurred upon exposure of pyrrolidine $\mathbf{7 1}$ to triflic anhydride and tetrabutylammonium triphenyldifluorosilicate (TBAT; Scheme 15). ${ }^{27}$ Cycloaddition of the resulting dipole across the pendant vinyl sulfide furnished $\mathbf{7 3}$ in $71 \%$ yield. Enol triflate $\mathbf{7 3}$ was then reduced to give the saturated side-chain in $\mathbf{7 4}$ in $89 \%$ yield by the action of $\mathrm{Pd} / \mathrm{C}$ under an $\mathrm{H}_{2}$ atmosphere. The enolate derived from $\mathbf{7 4}$ was treated with ethyl iodoacetate in the presence of HMPA followed by epimerization of the alkylation product to provide $\mathbf{7 5}$ in $58 \%$ yield from $\mathbf{7 4}$. Concomitant hydrolysis of the methyl ester and the acetonide protecting group gave $\mathbf{7 6}$ in $96 \%$ yield, an intermediate that contained suitable functional handles that could be elaborated into stemofoline $\mathbf{7 7}$. 


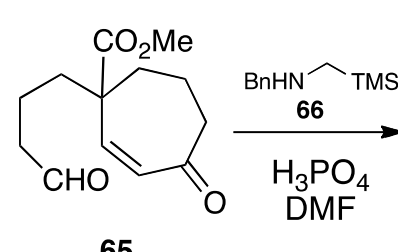

65

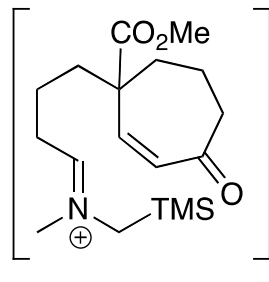

67

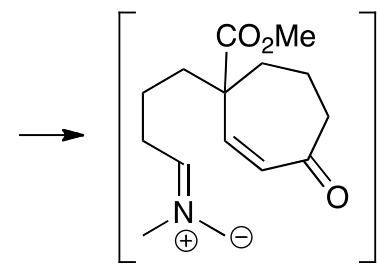

68

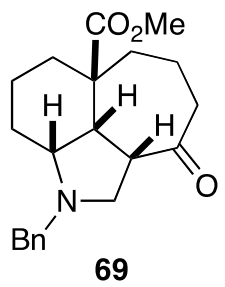

70

\section{Scheme 14}<smiles>CCS/C=C/C(=O)C[C@H]1C2OC(C)(C)O[C@H]2/C(=C\C(=O)CC)N1CSCC</smiles>

71

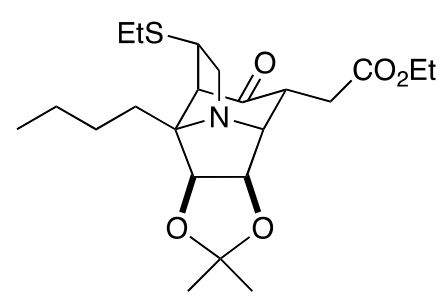

75
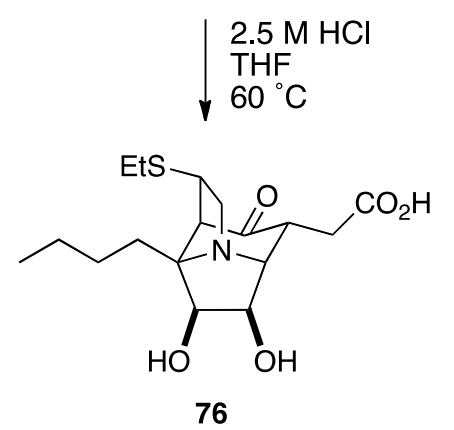

76
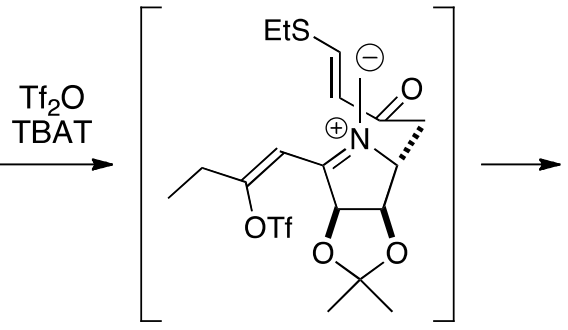

72

1. LDA

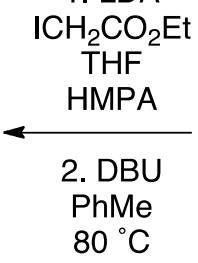

$80^{\circ} \mathrm{C}$

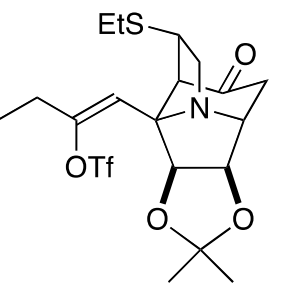

73

$\mathrm{Pd} / \mathrm{C}$

$\mathrm{H}_{2}$

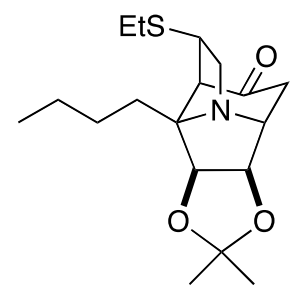

74

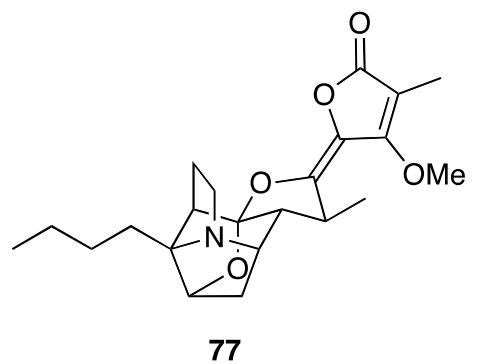

Scheme 15 


\subsection{Amaryllidaceae alkaloids}

Pandey and coworkers developed a AgF-mediated route to azomethine ylides starting from $N, N^{\prime}$ bis(trimethylsilylmethyl)alkyl amines and applied this method of dipole formation toward a formal total synthesis of the amaryllidaceae class of alkaloids. Exposure of $\mathbf{7 8}$ to AgF effected a double desilylation and oxidation to furnish a transient azomethine ylide dipole (Scheme 16). ${ }^{28,29}$ Cycloaddition of the dipole to the proximal enone fashioned tetracycle 79 in $56 \%$ yield. A base mediated hydrolysis of the benzoyl ester occurred with concomitant epimerization, giving $\mathbf{8 0}$ in $98 \%$ yield. Conversion of the hydroxyl group in $\mathbf{8 0}$ to a mesylate followed by reaction with KHMDS produced $\mathbf{8 2}$ in $65 \%$ yield via enolate $\mathbf{8 1}$. The alkene moiety in compound $\mathbf{8 4}$ was installed in $71 \%$ yield by a reductive elimination of an enol triflate derived from 83 using $\mathrm{Pd}_{(}\left(\mathrm{PPh}_{3}\right)_{4}$ and $\mathrm{Et}_{3} \mathrm{SiH}$. The Overman group had previously synthesized pancracine $\mathbf{8 7}$ from compound $\mathbf{8 4}$, thereby resulting in a formal synthesis of this alkaloid. 30,31 With the general cycloaddition strategy established, a next generation synthesis employed a chiral auxiliary to control the overall diasteroselectivity. Thus, exposure of compound $\mathbf{8 5}$ to $\mathrm{AgF}$ followed by reduction with $\mathrm{LiAlH}_{4}$ afforded 86 in $46 \%$ yield and with $63 \%$ enantiomeric excess after recrystallization. Tetracycle $\mathbf{8 6}$ was then used to complete an asymmetric formal synthesis of $\mathbf{8 7}$ and several related alkaloids.

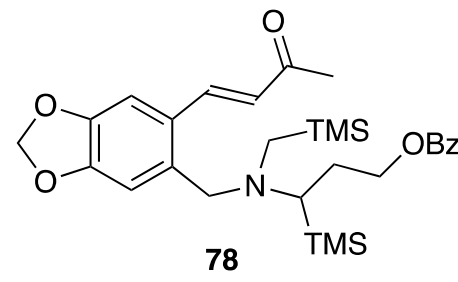

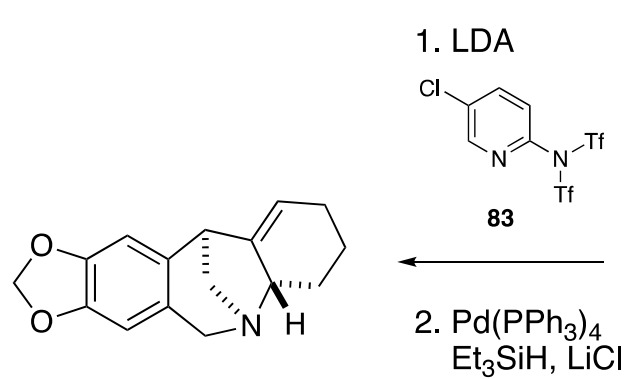

84
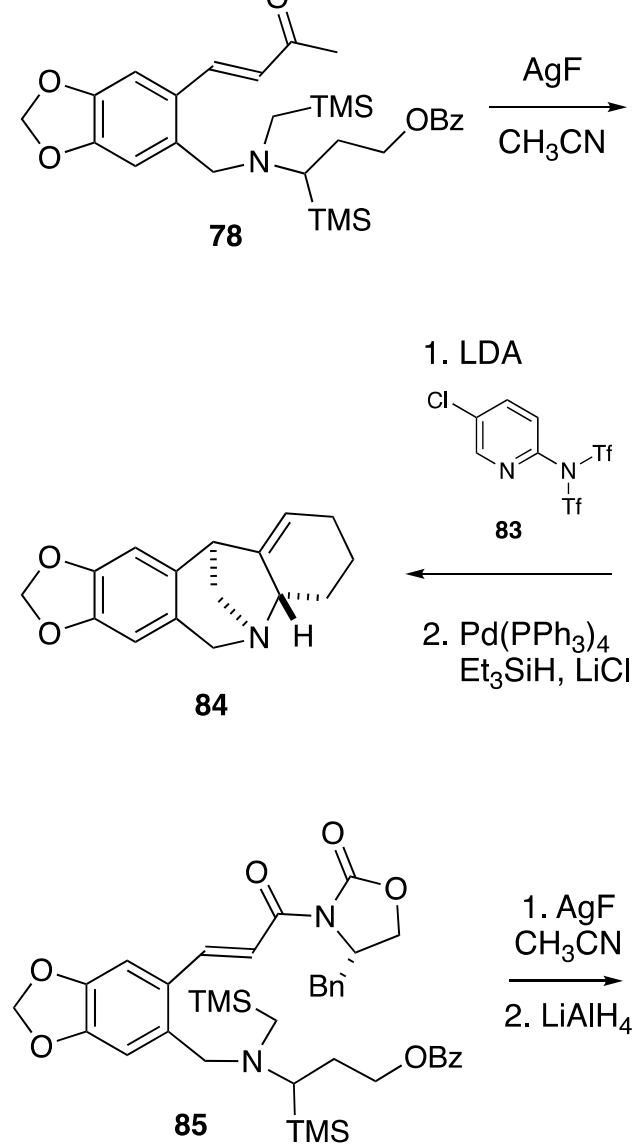

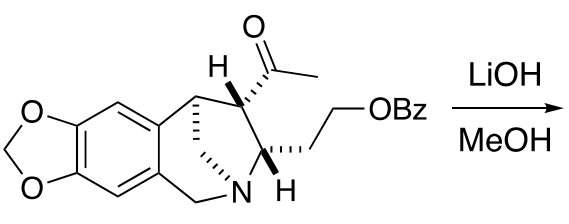

79

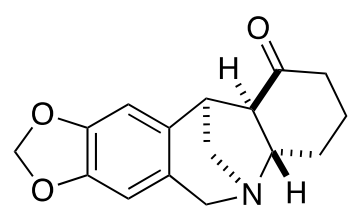

82

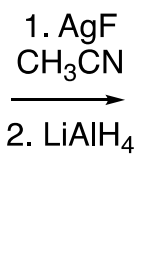

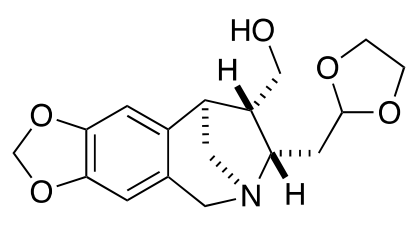

86

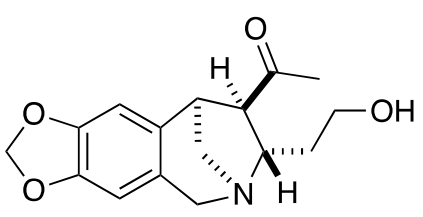

80

1. $\mathrm{MsCl}$ $\mathrm{Et}_{3} \mathrm{~N}$

2. KHMDS<smiles></smiles>

81

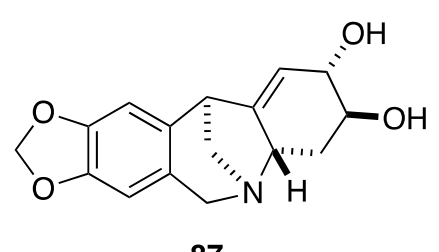

87

\section{Scheme 16}

\subsection{Daphnane alkaloids}

In an approach to the compact, polycyclic core of some daphnane alkaloids, the Bélanger group employed a sequential "Vilsmeier-Haack-azomethine ylide cycloaddition" sequence (Scheme 17). 32 Formamide 88 was reacted with $\mathrm{Tf}_{2} \mathrm{O}$ and 2,6-di-tert-butyl-4-methylpyridine (DTBMP) at rt to produce an iminium ion which 
underwent reaction with the silyl enol ether moiety followed by loss of triflate to produce iminium ion $\mathbf{8 9}$. Addition of $i \mathrm{Pr}_{2} \mathrm{EtN}$ to the reaction mixture then generated azomethine ylide dipole $\mathbf{9 0}$ that reacted with the $\alpha, \beta$-unsaturated ester to give tetracyclic $\mathbf{9 1}$, a species common to both the daphnilactone B-type alkaloids $\mathbf{9 2}$ and yuzurimine-type alkaloids 93.

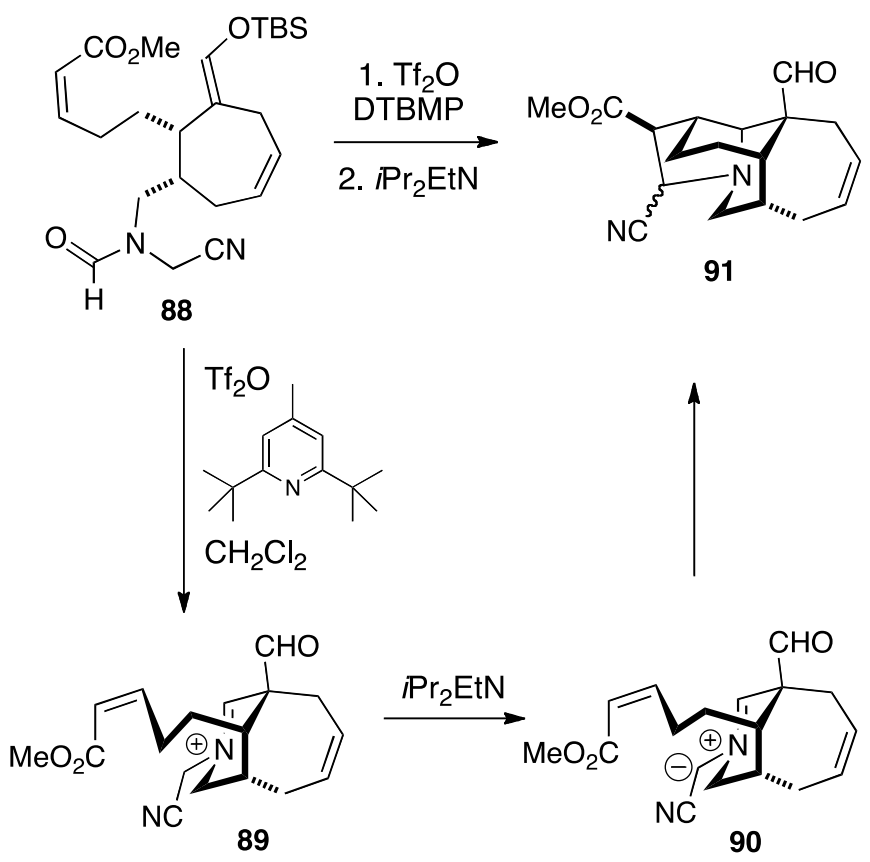

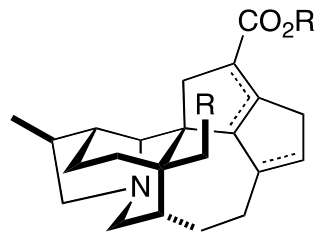

92

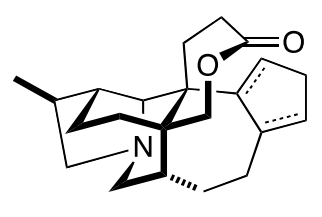

93

\section{Scheme 17}

\section{Carbonyl ylides}

\section{1. $R h($ II)-catalyzed reaction of diazo carbonyl substrates for ylide generation}

The creation of carbonyl ylide dipoles 95 (Scheme 18) from the reaction of $\alpha$-diazo compounds with ketones in the presence of $\mathrm{Rh}$ (II) catalysts7,33-38 has significantly broadened their applicability for natural product synthesis. ${ }^{39-41}$ The ease of generating the dipole, the rapid accumulation of polyfunctionality in a relatively small molecular framework, the high stereochemical control of the subsequent [3+2]-cycloaddition, and the fair predictability of its regiochemistry have contributed to the popularity of the reaction. 42,43 When the reacting components are themselves cyclic or have ring substituents, complex multicyclic arrays, such as those contained in drugs and natural products, can be constructed in a single step.

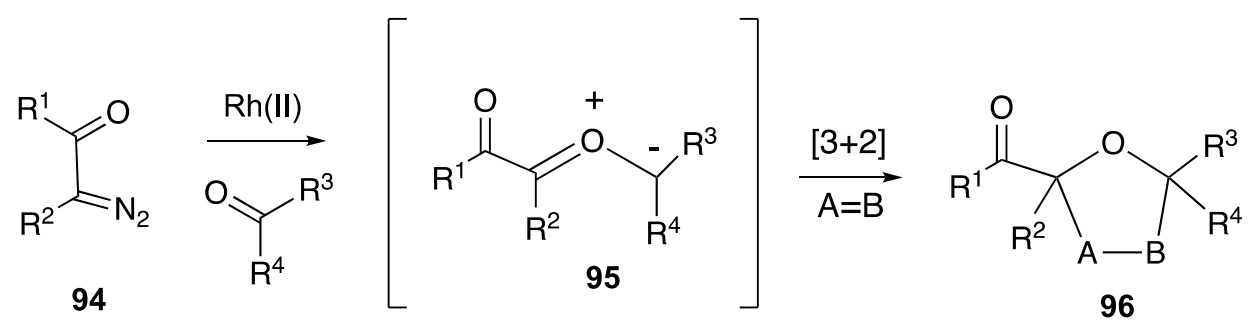

\section{Scheme 18}




\section{Alkaloid target synthesis}

\section{1. ( \pm )-Aspidophytine}

One of the early examples of the trapping of a carbonyl ylide dipole with a tethered $\pi$-bond for alkaloid synthesis was found as the central step in my laboratory's approach toward the complex pentacyclic alkaloid ( \pm )aspidophytine 101.44,45 The key sequence of reactions involved a 1,3-dipolar cycloaddition of the 'push-pull' dipole 98 across the indole $\pi$-system. The exo-cycloadduct 99 was the exclusive product isolated from the Rh(II)catalyzed reaction of $\mathbf{9 7}$ (Scheme 19). It was assumed that in this case, the bulky tert-butyl ester functionality blocks the endo approach thereby resulting in cycloaddition taking place from the less-congested exo face. Treatment of the resulting dipolar cycloadduct 99 with $\mathrm{BF}_{3} . \mathrm{OEt}_{2}$ induces a domino fragmentation cascade. The reaction proceeds by an initial cleavage of the oxabicyclic ring and formation of a transient $N$-acyliminium ion, which reacts further with the adjacent tert-butyl ester and sets the required lactone ring present in aspidophytine. A three-step sequence was then used to remove both the ester and $\mathrm{OH}$ groups from lactone 100. Subsequent functional group manipulations allowed for the high-yielding conversion of 100 into ( \pm )aspidophytine 101.

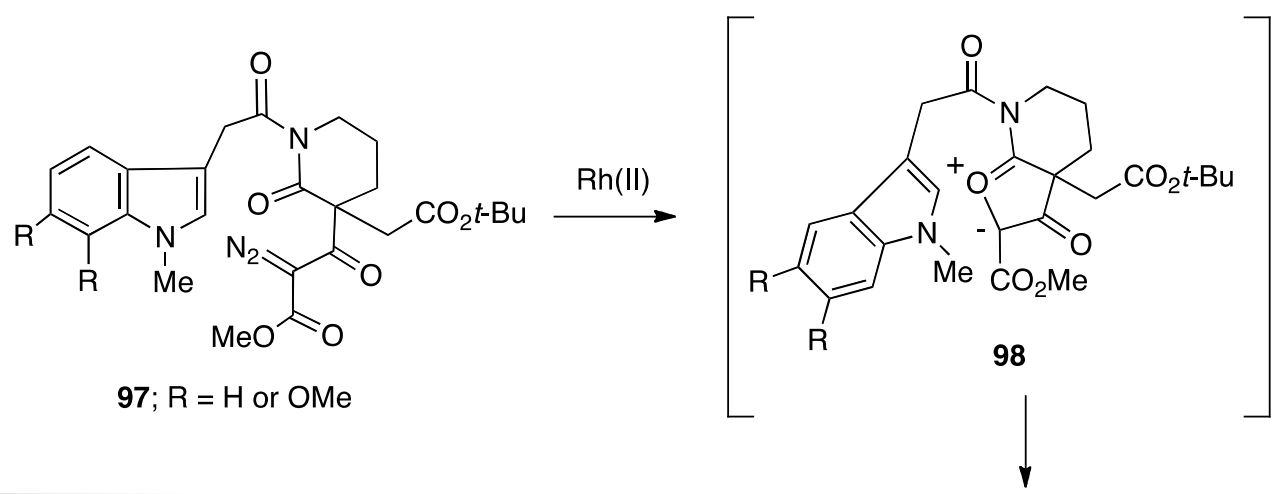

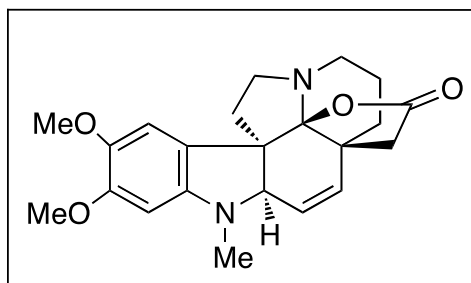

$( \pm$-Aspidophytine 101

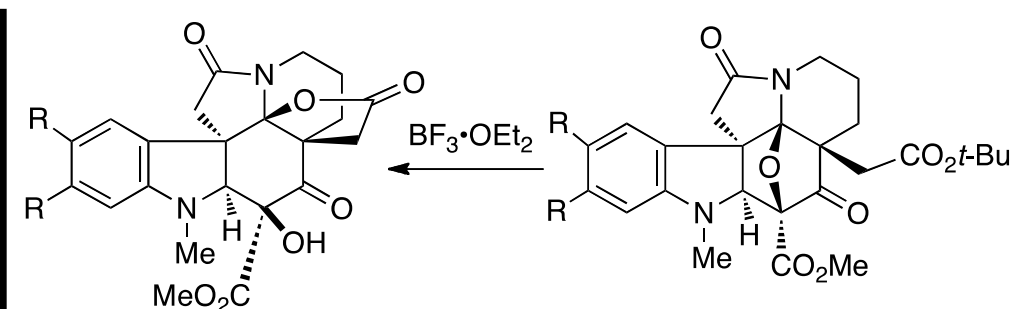

99; $97 \%$

$100 ; 70 \%$

\section{Scheme 19}

\subsection{Synthesis of the kopsifoline skeleton}

As a further extension of "push-pull" dipole cycloaddition chemistry, the Rh(II)-catalyzed cyclization/cycloaddition cascade was applied toward the hexacyclic framework of the kopsifoline alkaloids. The kopsifolines 104 are structurally intriguing compounds, related to and possibly derived from an aspidospermatype alkaloid precursor 102. A possible biogenetic pathway to the kopsifolines from 102 could involve an intramolecular epoxide-ring opening followed by loss of $\mathrm{H}_{2} \mathrm{O}$ as shown in Scheme 20. The interesting biological activity of these compounds combined with their fascinating and synthetically challenging structure, make them attractive targets for synthesis. Using the metal-catalyzed domino reaction as a key step, the heterocyclic skeleton of the kopsifolines could eventually be built by a 1,3-dipolar cycloaddition of a "push-pull" carbonyl 
ylide dipole derived from $\alpha$-diazo ketoester 105 across the indole $\pi$-bond. Ring-opening of the resulting cycloadduct 106 followed by a reductive dehydroxylation step produced the critical silyl enol ether 107 necessary for the final F-ring closure. The facility and stereoselectivity of the key cycloaddition reaction was investigated in more detail using some model substrates. It was found that the heterocyclic skeleton of the kopsifoline alkaloid family $\mathbf{1 0 8}$ could readily be constructed by the proposed sequence of reactions outlined in Scheme $21.46,47$ The isolation of $\mathbf{1 0 6}$ as a single diastereomer was rationalized by recognizing that the indole moiety approaches the dipole from the least sterically encumbered position. Ring-opening of the resulting cycloadduct $\mathbf{1 0 6}$ followed by a reductive dehydroxylation step resulted in the formation of the silyl enol ether 107 necessary for the final F-ring closure of the kopsifoline skeleton (i.e., formation of 108).

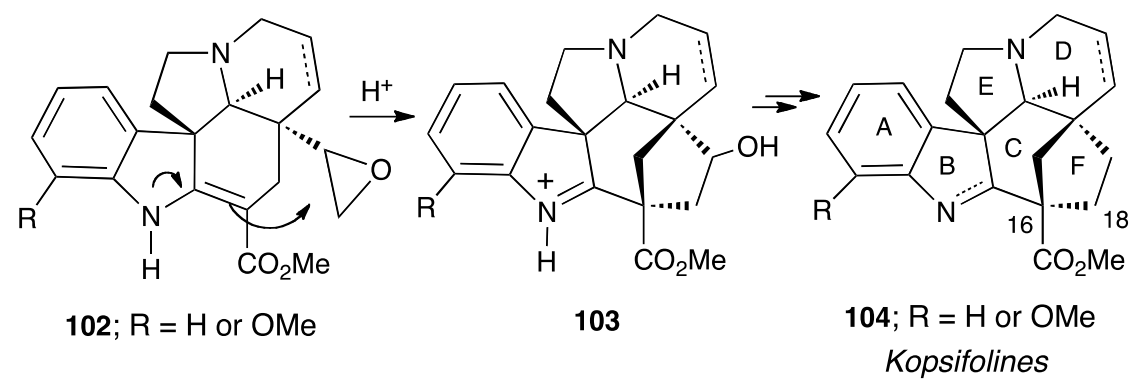

\section{Scheme 20}

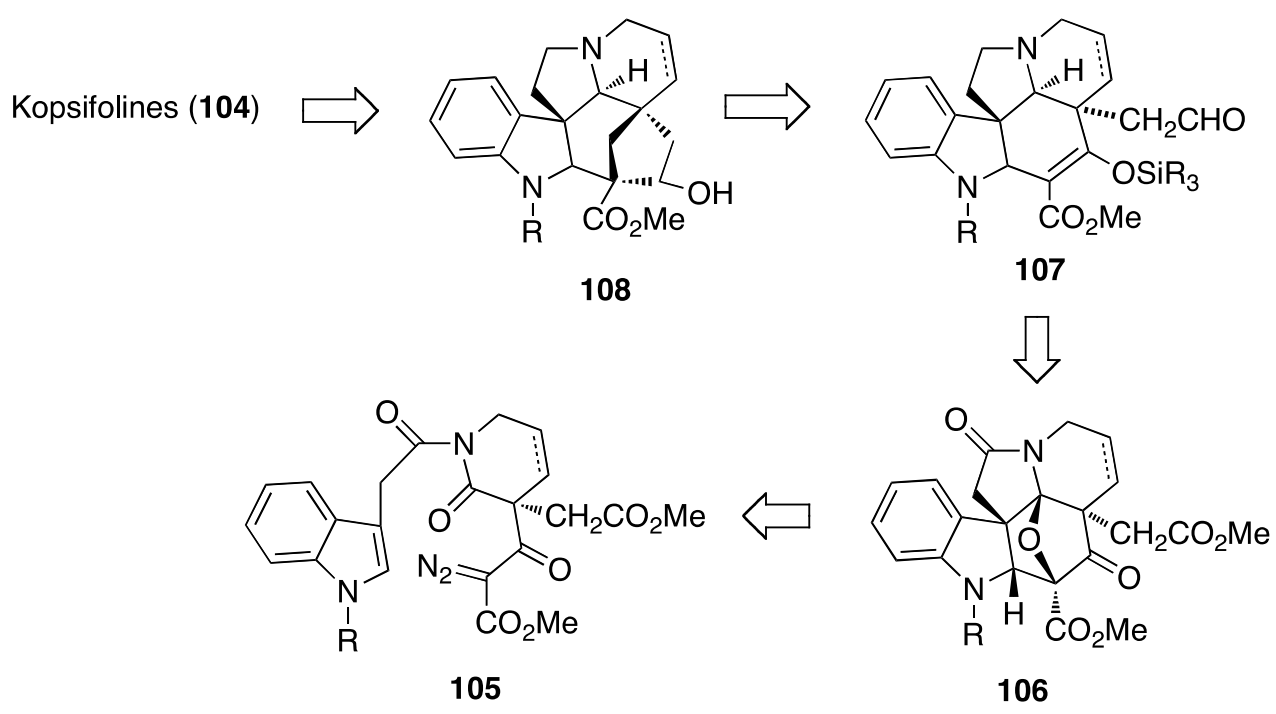

\section{Scheme 21}

\subsection{Vinca and tacaman alkaloids}

The total synthesis of several members of the vinca and tacaman class of indole alkaloids has also been accomplished using "push-pull' dipoles in the critical cycloaddition step. 48,49 The central step in the synthesis consists of an intramolecular [3+2]-cycloaddition reaction of $\alpha$-diazo indoloamide 109, which delivers the pentacyclic skeleton of the natural product in excellent yield (Scheme 22). The acid lability of the oxabicyclic structure was exploited to establish the trans-D/E-ring fusion of ( \pm )-3H-epivincamine 112. Finally, a base induced ketoamide ring contraction was utilized to generate the $E$-ring of the natural product. A variation of the cascade sequence of reactions used to synthesize $( \pm)$-3H-epivincamine $\mathbf{1 1 2}$ was also employed for the synthesis of the tacaman alkaloid ( \pm )-tacamonine 113. 
<smiles>[R]C(=C)CC([R])C(=O)N1CCc2c(n(C(=O)C(=N)OCC)c3ccccc23)C1=O</smiles>

109

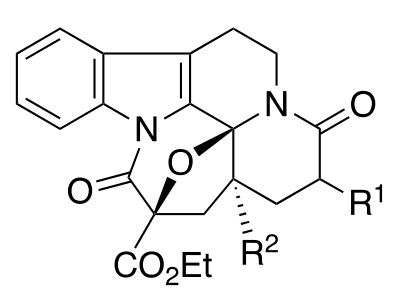

110; $R^{1}=\mathrm{Et} ; \mathrm{H} ; 95 \%$

$111 ; R^{2}=E t ; H ; 90 \%$

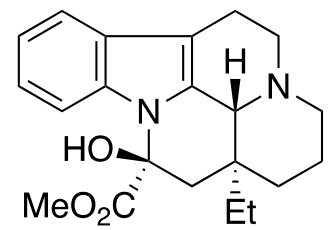

112; ( \pm )-3H-epivincamine

$\mathrm{R}^{1}=\mathrm{H}$
$\mathrm{R}^{2}=\mathrm{Et}$

$\mathrm{R}^{1}=\mathrm{Et}$

$\mathrm{R}^{2}=\mathrm{H}$

113; ( \pm )-tacamonine

\section{Scheme 22}

\section{$5.4(-)-$ Vindoline}

Even though the Boger group's synthesis of the vinca alkaloid family does not involve a Rh-carbenoid intermediate, their approach proceeds through a related "push-pull" dipole intermediate and is based on an intramolecular [4 + 2]/[3 + 2]-cycloaddition reaction of a 1,3,4-oxadiazole heterocycle. $50-55$ This unique domino cascade was used to assemble the fully functionalized pentacyclic ring system of vindoline 118 in a single step that forms four $\mathrm{C}-\mathrm{C}$ bonds and three rings while introducing all the requisite functionality and setting all six stereocenters within the central ring including three contiguous and four total quaternary centers (Scheme 23). The reaction leading to $\mathbf{1 1 7}$ is initiated by an intramolecular inverse electron demand Diels-Alder cycloaddition of the 1,3,4-oxadiazole 114 with the tethered enol ether. Loss of nitrogen from the initial Diels-Alder cycloadduct 115 provides the "push-pull" carbonyl ylide 116, which then undergoes a subsequent 1,3-dipolar cycloaddition with the tethered indole. Importantly, the diene and dienophile substituents complement and reinforce the [4+2]-cycloaddition regioselectivity dictated by the linking tether. The relative stereochemistry in the cycloadduct is controlled by a combination of (1) the dienophile geometry and (2) an exclusive endo indole $[3+2]$-cycloaddition sterically directed to the $R$-face opposite the newly formed fused lactam. This endo diastereoselection for the 1,3-dipolar cycloaddition has been attributed to a conformational (strain) preference dictated by the dipolarophile tether. ${ }^{54}$ Cycloadduct 117 was eventually transformed into the natural product vindoline 118 in several additional steps. Extension of these cascade studies by the Boger group also provided for a total synthesis of the bis-indole alkaloids vinblastine and vincristine. 55 


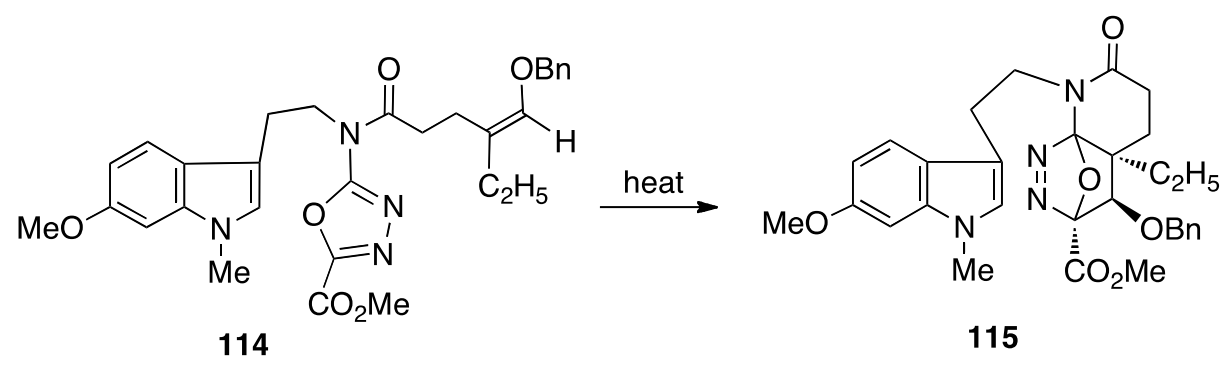

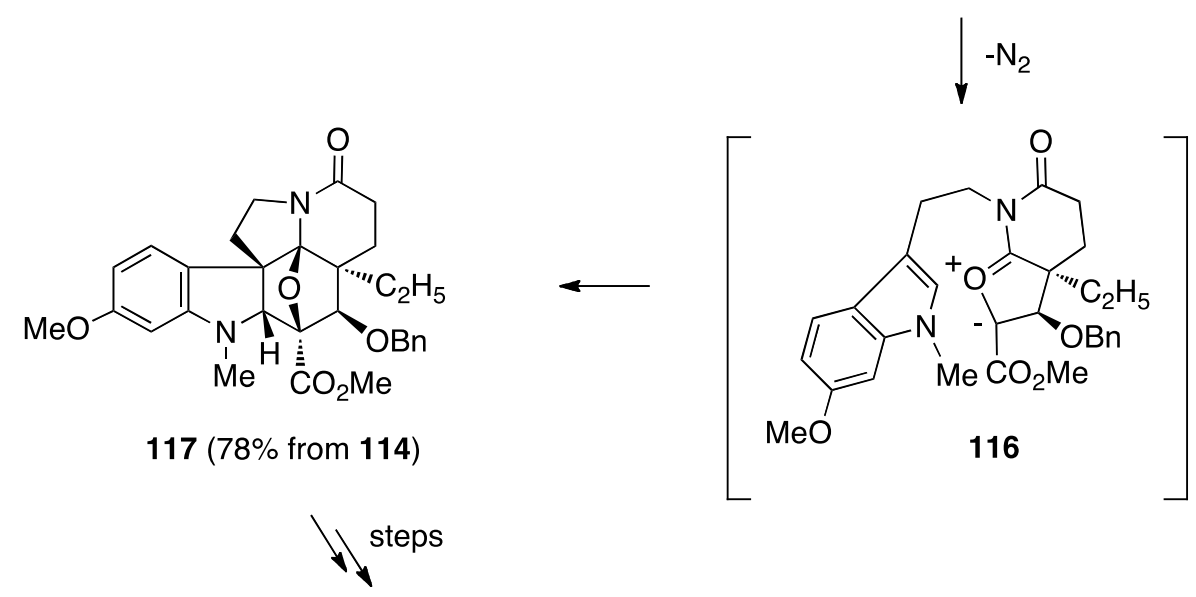

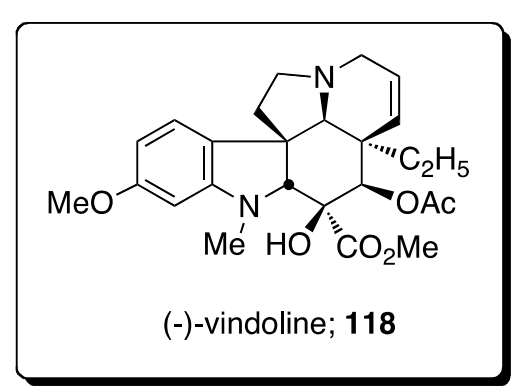

\section{Scheme 23}

\section{5 ( \pm )-Vallesamidine}

Given the success in forming novel azabicyclic systems derived from an intramolecular isomünchnone cycloaddition/ $\mathrm{N}$-acyliminium ion cyclization sequence, this domino strategy was also used for a formal synthesis of vallesamidine 124 via the key Heathcock intermediate 123 (Scheme 24).56,57 Thus, N-malonylacylation of the precursor amide was carried out followed by a standard diazo transfer reaction to produce the requisite $\alpha$ diazoimide 119. The reaction of $\mathbf{1 1 9}$ with a Rh(II)-catalyst gave cycloadduct 120, which underwent a TMSOTf catalyzed ring opening to furnish enamide 121 in 78\% yield. With the ring-opened lactam in hand, a BartonMcCombie deoxygenation reaction delivered 122 in $88 \%$ yield. 58 Utilization of the sequential saponification/ decarboxylation protocol afforded enamide 123.59 This sequence constitutes a formal synthesis of ( \pm )vallesamidine 124, based on the successful conversion of 123 into 124 by Heathcock and Dickman. 56,57 
<smiles>CCOC(=O)C(=N)C(=O)N1CCCC(CC)(CC/C=C\c2ccccc2[N+](=O)[O-])C1=O</smiles>

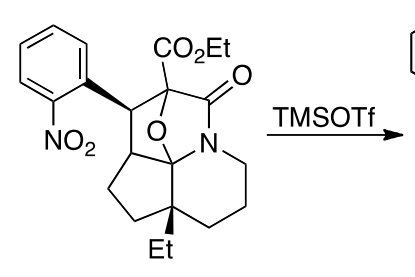

120; $79 \%$<smiles>CCOC(=O)C1(O)C(=O)N2CCCC3(CC)CCC(=C23)[C@H]1c1ccccc1[N+](=O)[O-]</smiles>

121

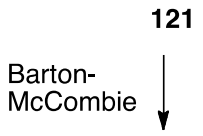

(士)-vallesamidine; 124<smiles></smiles>

123<smiles>CCOC(=O)[C@H]1C(=O)N2CCCC3(CC)CCC(=C23)[C@H]1c1ccccc1[N+](=O)[O-]</smiles>

122

\section{Scheme 24}

\section{6 ( \pm )-Lycopodine}

Another application of the domino cascade process toward the construction of alkaloids involved the synthesis of (士)-lycopodine 129 (Scheme 25). 60 The isomünchnone cycloadduct 126 was formed from the Rh(II)-catalyzed reaction of diazo imide 125 and was found to be the precursor of the key Stork intermediate 128 (via 127). Formation of 128 from 127 occurred by way of a Pictet-Spengler cyclization of the $N$-acyliminium ion derived from 126. Central to this strategy was the expectation that the bicyclic iminium ion originating from 126 would exist in a chairlike conformation. ${ }^{61-63}$ Indeed, cyclization of the aromatic ring onto the $\mathrm{N}$-acyliminium ion center readily occurred from the axial position. ${ }^{64-66}$ The rearranged product 127 was then converted into the key intermediate 128 previously used by Stork for the synthesis of ( \pm )-lycopodine $\mathbf{1 2 9 . 6 1 , 6 2}$<smiles>C=C[C@H](Cc1cccc(OC)c1)C[C@H](C)CC(=O)N(C)C(=O)C(=[W])[Hg]c1ccccc1</smiles>

125<smiles>CCOC(=O)[C@@]12C[C@H](Cc3cccc(OC)c3)[C@@H](C)C[C@H](C)C1N(Cc1ccccc1)C2=O</smiles>

$\mathrm{Bn}$

126

$\mathrm{BF}_{3} / \mathrm{AcOH}$

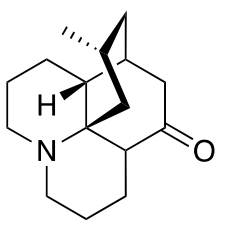

(士)-lycopodine; 129

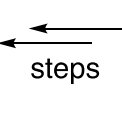

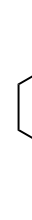

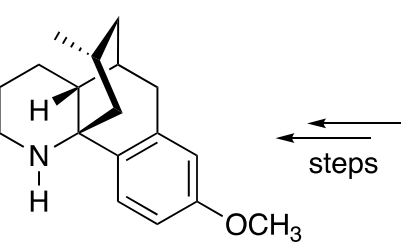

128

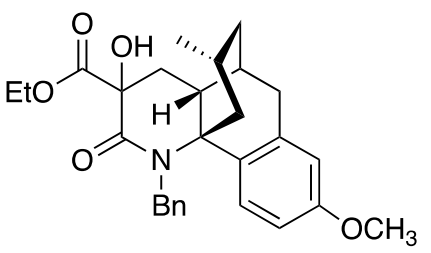

127 


\subsection{Indolizidine alkaloids}

A further implementation of the cascade methodology involves the efficient assembly of the indolizidine ring system by using the $\mathrm{Rh}(\mathrm{II})$-catalyzed [3+2]-dipolar cycloaddition of the phenylsulfonyl substituted diazopyrrolidinone $\mathbf{1 3 0}$ with an appropriately substituted dipolarophile (Scheme 26). The resultant pyridone 133 represents a very versatile synthon. As depicted in Scheme 26, structural manipulation of the pyridinone ring and subsequent functional group interconversions provides access to several indolizidine alkaloids. ${ }^{67-70}$ The $_{6}$ hydroxyl substituent, protected as triflate 134, allows for an assortment of cross coupling-possibilities. The Padwa group demonstrated the versatility of the method through the synthesis of the angiotensin converting enzyme inhibitor (-)-A58365A 135, ( \pm )-ipalbidine 136, $\beta$-carbolinone 137 and a variety of other novel indolizidine-based compounds. 70<smiles>[R]C1CCC(=O)N1C(=O)C([N+]=[N-])=[N+]=[N-]</smiles>

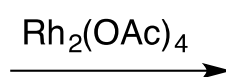<smiles>[R]C1CCC2=[O+]C(S(=O)(=O)Oc3ccccc3)C(=O)N21</smiles>

131<smiles></smiles><smiles>[R]c1cc([R])c(=O)n2c1CCC2[R]</smiles><smiles>CC(C)P[SbH](=O)O</smiles><smiles>[R]C1CC2(SOc3ccccc3)C(=O)N1C1CCC12[R]</smiles>

133; $\mathrm{R}^{3}=\mathrm{OH}$ 134; $R^{3}=\mathrm{OTf}$ 132

$$
\downarrow \downarrow \text { steps }
$$<smiles>O=C(O)CCc1cc(O)c2n(c1=O)[C@H](C(=O)O)CC2</smiles>

Ace Inhibitor; 135 A58365A<smiles>CC1=C([Al])CN2CCCC2C1</smiles>

$\mathrm{Ar}=p-\mathrm{HOC}_{6} \mathrm{H}_{4}$ ipalbidine; 136<smiles>[R2]c1c2n(c(=O)c3[nH]c4ccccc4c13)CCC2</smiles>

$\beta$-carbolinone core; 137

\section{Scheme 26}

\subsection{Mappicine ketone}

An efficient synthesis of the naturally occurring oxoindolizino quinoline mappicine ketone $\mathbf{1 4 4}$ has been carried out by Greene and coworkers by making use of pyridone 139a as a key intermediate. ${ }^{71}$ The synthesis of 144 began with formation of the known cycloadduct $139 a\left(R_{1}=H ; R_{2}=C_{2} M e\right)$ by cycloaddition of the isomünchnone dipole derived from diazo sulfone 138 with methyl acrylate (Scheme 27). 67-70 This multistep sequence proceeded smoothly and in high yield when catalyzed by rhodium(II) acetate. Hot aqueous 
hydrobromic acid then effected decarbomethoxylation of $139 \mathrm{a}$ to give $139 \mathrm{~b}$ in $82 \%$ yield. Etherification of $139 \mathrm{~b}$ with commercially available (E)-1-bromo-2-pentene and cesium carbonate in dimethylformamide produced the expected substitution product 139c, which cleanly underwent a Claisen rearrangement in refluxing chlorobenzene to afford the desired rearranged derivative 140 in $74 \%$ overall yield. This transformation is a rare example of a Claisen rearrangement taking place in a hydroxypyridone system $70,72,73$ The $\alpha$-hydroxypyridone 140 was then converted into its triflate derivative under standard conditions. This was followed by Stille coupling with tetramethyltin to provide $\alpha$-methyl pyridone 141 in $84 \%$ yield. In the presence of rhodium(III) chloride in hot ethanol, compound 141 was rapidly isomerized to olefin 142a (91\%). The success of this key transformation derives from the carbon symmetry of the $\beta$-substituent in pyridone 141. Oxidation of 142a in two steps then selectively generated the Friedländer substrate $\mathbf{1 4 2 b}$, which was reacted with 0 -aminobenzaldehyde to give oxoindolizino quinoline 143 in $73 \%$ yield. Ozonolysis of 143 in $\mathrm{CH}_{2} \mathrm{Cl}_{2} / \mathrm{MeOH}$ at $-78{ }^{\circ} \mathrm{C}$ accomplished selective double-bond cleavage in $\mathbf{1 4 3}$ to provide mappicine ketone 144.
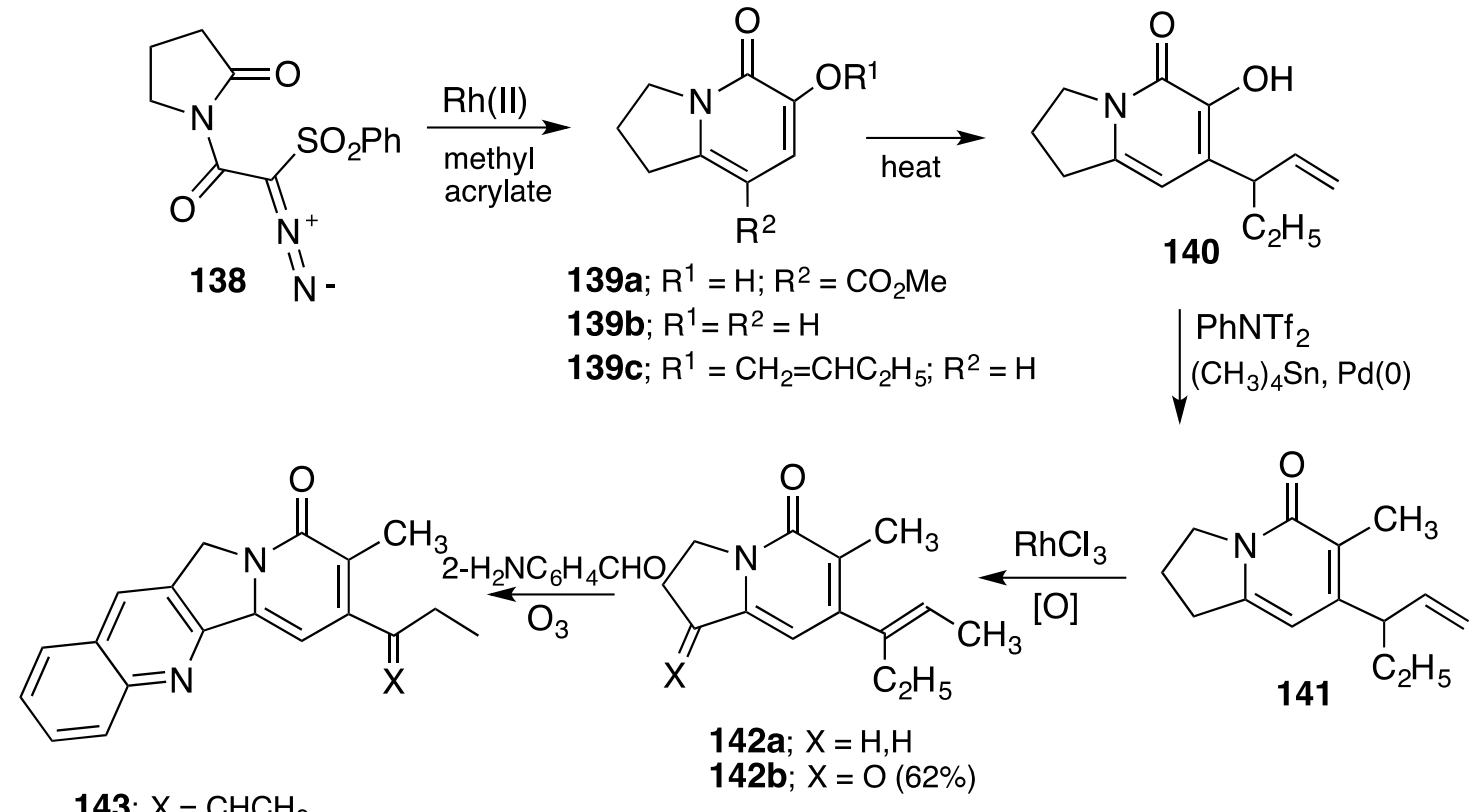

144; $\mathrm{X}=\mathrm{O}$; mappicine ketone $(60 \%)$

\section{Scheme 27}

\section{9 ( \pm )-Campothecin}

A related synthesis of racemic camptothecin $\mathbf{1 4 5}$ was also carried out by Greene and coworkers soon thereafter and is similarly based on the isomünchnone dipole strategy. ${ }^{74}$ The starting point commenced from the readily available hydroxyl-pyridone 139b (Scheme 28). Subsequent steps include a Claisen rearrangement of a functionalized allylic ether, a hindered Heck coupling, and a Friedländer condensation. 
<smiles>[N-]=[N+]=C(SOc1ccccc1)C(=O)N1CCCC1=O</smiles>

138

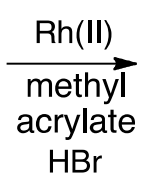

$\mathrm{HBr}$<smiles>O=c1c(O)ccc2n1CCC2</smiles>

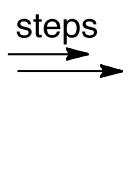

$139 b$<smiles></smiles>

(土)-camptothecin; 145

\section{Scheme 28}

\subsection{0 ( \pm )-Tashiromine}

Recently, Suga and coworkers have reported on a highly enantioselective 1,3-dipolar cycloaddition reaction between several 3-(2-alkenoyl)-2-oxazolidinones and carbonyl ylides that were generated from the Rh(II)catalyzed reaction of $\mathrm{N}$-diazoacetyl lactams (Scheme 29). ${ }^{75} \mathrm{~N}$-Diazoacetyl lactams that possess 5-, 6-, and 7membered rings were transformed to the corresponding epoxy-bridged indolizidines, quinolizidines, and 1azabicyclo[5.4.0] undecanes 148 with good to high enantioselectivities according to this method. A regio- and stereoselective ring-opening of the epoxy-bridged indolizidine cycloadduct $\mathbf{1 4 8}$ gave the corresponding alcohol as a single diastereomer. The sequence of an asymmetric cycloaddition reaction followed by ring-opening was applied to the syntheses of several chiral indolizidine derivatives, including (+)-tashiromine 150.75
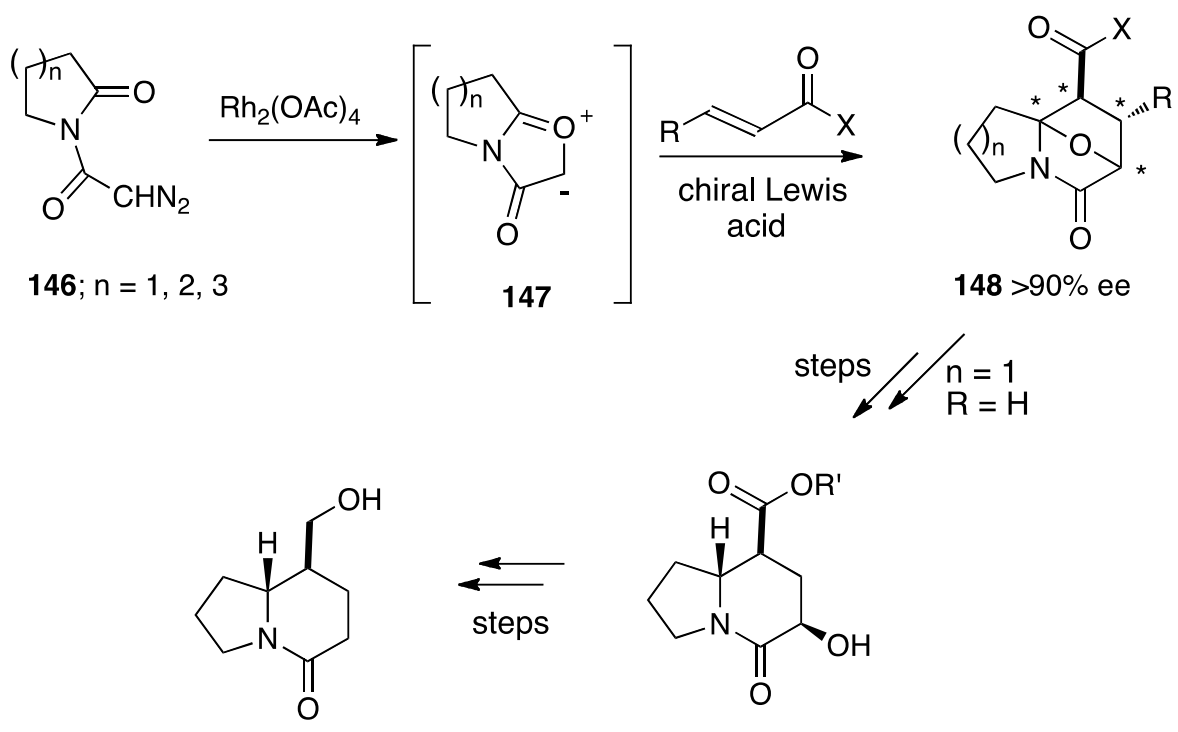

150; (+)-tashiromine

$$
\text { (1) }
$$

\section{Scheme 29}

\subsection{Atorvastatin}

The well known pharmaceutical drug Atorvastatin, marketed under the trade name Lipitor, is a member of the drug class known as statins, which are used primarily for lowering blood cholesterol and for prevention of events associated with cardiovascular disease. Since Atorvastatin $\mathbf{1 5 3}$ is one of the top selling pharmaceuticals, it has been the subject of many synthetic studies aimed to improve its preparation, particularly the pyrrole core and pendant chiral diol. In a recent report, Gribble and Lopchik described the preparation of $\mathbf{1 5 3}$ in seven steps from commercially 4-fluorophenylacetic acid. ${ }^{76}$ The key step involved the treatment of 151 with $N, N^{\prime}$ - 
diisopropylcarbodiimide (DIPC) followed by a 1,3-dipolar cycloaddition of the resulting münchnone mesoionic heterocycle 152 with N,3-diphenylpropiolamide as shown in Scheme 30.77

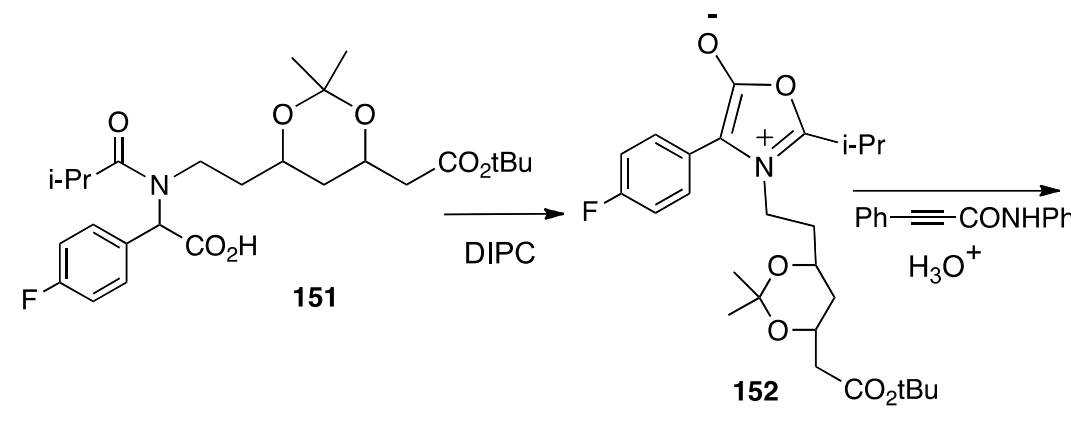

Scheme 30

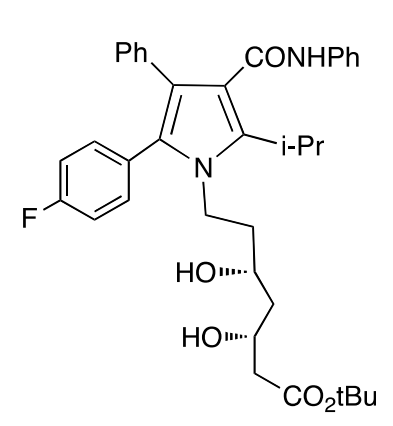

153; atorvastatin

\section{Conclusions}

The application of the cycloaddition of both azomethine and carbonyl ylide dipoles for the synthesis of various alkaloids as described in this mini-review article spans a broad spectrum of organic chemistry. The regio- and stereoselectivity of the 3+2-cycloaddition reaction is now well established, making it an attractive strategic disconnection for synthetic design of various alkaloids. As is the case in all new areas of research, future investigations of the chemistry of these dipolar cycloadditions for complex heterocyclic synthesis will be dominated by the search for enantioselective synthesis. Future developments will also depend on gaining a greater understanding of the mechanistic details of this fascinating and synthetically important process.

\section{Acknowledgements}

We greatly appreciate the financial support provided by the National Science Foundation (grant CHE-1057350) and the Camille and Henry Dreyfus Foundation.

\section{References}

1. Synthetic Applications of 1,3-Dipolar Cycloaddition Chemistry Towards Heterocycles,; Natural Products, Padwa, A.; Pearson; W. H. Wiley-Interscience: Hoboken, NJ, 2003.

2. Huisgen, R. Angew. Chem., Int. Ed. Engl. 1963, 2, 565.

https://doi.org/10.1002/anie.196305651

3. Huisgen R. in 1,3-Dipolar Cycloaddition Chemistry, $1^{\text {st }}$ Ed.; Padwa, A., Ed.; Wiley-Interscience: New York, NY; 1984, Vol. 1, 1.

4. Houk, K. N.; Yamaguchi K. in 1,3-Dipolar Cycloaddition Chemistry, $1^{\text {st }}$ Ed.; Padwa, A., Ed.; WileyInterscience: New York, NY; 1984; Vol. 2, 407. 
5. Suga, H.; Itoh K. in Methods and Applications of Cycloaddition Reactions in Organic Syntheses, $1^{\text {st }}$ Ed.; Nishiwaki, N.. Ed.; Wiley-Interscience: Hoboken, NJ, 2014, 175.

https://doi.org/10.1002/9781118778173.ch07

6. Nair, V.; Suja, T. D. Tetrahedron 2007, 63, 12247. https://doi.org/10.1016/i.tet.2007.09.065

7. Hodgson, D. M.; Labande, A. H.; Muthusamy, S. Org. React. 2013, 80, 133.

8. Coldham, I.; Hufton, R. Chem. Rev. 2005, 105, 2765. https://doi.org/10.1021/cr040004c

9. Coldham, I.; Dobson, B. C.; Fletcher, S. R.; Franklin, A. I. Eur. J. Org. Chem. 2007, 2676. https://doi.org/10.1002/ejoc.200700045

10. Badarinarayana, V.; Lovely, C. J. Tetrahedron Lett. 2007, 48, 2607. https://doi.org/10.1016/j.tetlet.2007.02.008

11. Burrell, A. J.; Coldham, I.; Watson, L.; Oram, N.; Pilgram, C. D.; Martin, N. G. J. Org. Chem. 2009, 74, 2290. https://doi.org/10.1021/jo8019913

12. Banwell, M.; Flynn, B.; Hockless, D. Chem. Commun. 1997, 2259. https://doi.org/10.1039/a705874h

13. Coldham, I.; Coles, S. J.; Crapnell, K. M.; Fernàndez, J-C.; Haxell, T.F. N.; Hursthouse, M. B.; Moseley J. D.; Treacy, A. B. Chem. Commun. 1999, 1757. https://doi.org/10.1039/a904667d

14. Coldham, I.; Pih, S. M.; Rabot, R. Synlett 2005, 1743. https://doi.org/10.1055/s-2005-871538

15. Gao, N. M.; Banwell, G.; Willis, A. C. Org. Lett. 2017, 19, 162. https://doi.org/10.1021/acs.orglett.6b03465

16. Dietz, J.; Martin, S. Tetrahedron Lett. 2011, 52, 2048. https://doi.org/10.1016/j.tetlet.2010.10.038

17. Shanahan, C. S.; Fang, C.; Paull, D. H.; Martin, S. F. Tetrahedron 2013, 69, 7592. https://doi.org/10.1016/j.tet.2013.03.104

18. Bruggemann, M.; McDonald, A. I.; Overman, L. E.; Rosen, M. D.; Schwink, L.; Scott, J. P. J. Am. Chem. Soc. 2003, 125, 15284. https://doi.org/10.1021/ja0388820

19. Padwa, A.; Dent, W.; Parker, K. A.; Cohen, I. D. Tetrahedron Lett. 1984, 25, 4917. https://doi.org/10.1016/S0040-4039(01)81607-5

20. Padwa, A.; Dent, W. J. Org. Chem. 1987, 52, 235. https://doi.org/10.1021/jo00378a013

21. Padwa, A.; Chen, Y. Y.; Chiacchio, U.; Dent, W Tetrahedron 1985, 41, 3529. https://doi.org/10.1016/S0040-4020(01)96706-7

22. Westling, M.; Smith, R.; Livinghouse, T. J. Org. Chem. 1986, 51, 1159. https://doi.org/10.1021/jo00358a001

23. Pearson, W. H.; Mi, Y. Tetrahedron Lett. 1997, 38, 5441. https://doi.org/10.1016/S0040-4039(97)01217-3

24. Clark, R. B.; Pearson, W. H. Org. Lett. 1999, 1, 349. https://doi.org/10.1021/ol990677v

25. Pearson, W. H.; Kropf, J. E.; Choy. A. L.; Lee, Y.; Kampf, J. W. J. Org. Chem. 2007, 72, 4135. https://doi.org/10.1021/jo0703799 
26. Ma, D.; Cheng, H.; Huang, C.; Lu, L. Tetrahedron Lett. 2015, 56, 2492. https://doi.org/10.1016/j.tetlet.2015.03.097

27. Carra, R. J.; Epperson, M. T.; Gin, D. Y. Tetrahedron 2008, 64, 3629. https://doi.org/10.1016/j.tet.2008.02.008

28. Pandy, G.; Kumar, R.; Banerjee, P.; Puranik, V. G. Eur. J. Org. Chem, 2011, 4571. https://doi.org/10.1002/ejoc.201100601

29. Pandey, G.; Gadre, S. R. Pure Appl. Chem. 2012, 84, 1597. https://doi.org/10.1351/PAC-CON-11-10-12

30. Overman, L. E.; Shim. J. J. Org. Chem. 1991, 56, 5005. https://doi.org/10.1021/jo00017a002

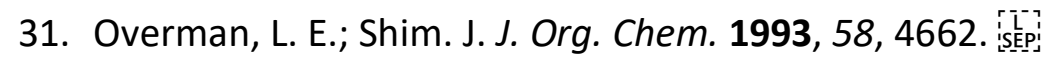
https://doi.org/10.1021/jo00069a032

32. Bélanger, G.; Boudreault, J.; Lévesque, F. Org. Lett. 2011, 13, 6204. https://doi.org/10.1021/ol202629d

33. Doyle, M. P.; McKervey, M. A.; Ye, T. in Modern Catalytic Methods for Organic Synthesis with Diazo Compounds: from Cyclopropanes to Ylides, Wiley: New York, 1995.

34. Doyle, M. P. Chem. Rev. 1986, 86, 919. https://doi.org/10.1021/cr00075a013

35. Ye, T.; McKervey, M. A. Chem. Rev. 1994, 1091. https://doi.org/10.1021/cr00028a010

36. Padwa, A.; Hornbuckle, S. F. Chem. Rev. 1991, 263. https://doi.org/10.1021/cr00003a001

37. Padwa, A.; Krumpe, K. E. Tetrahedron, 1992, 5385. https://doi.org/10.1016/S0040-4020(01)88298-3

38. Padwa, A.; Weingarten, M. D Chem. Rev. 1996, 223. https://doi.org/10.1021/cr950022h

39. Padwa, A.; Curtis, E. A.; Sandanayaka, V. P. J. Org. Chem. 1997, 62, 1317. https://doi.org/10.1021/j0961574i

40. Dauben, W. G.; Dinges, J.; Smith, T. C. J. Org. Chem. 1993, 58, 7635. https://doi.org/10.1021/jo00079a004

41. Koyama, H.; Ball, R. G.; Berger, G. D. Tetrahedron Lett. 1994, 35, 9185. https://doi.org/10.1016/0040-4039(94)88460-9

42. Padwa, A. Angew. Chem. Int. Ed. Engl. 1976, 15, 123.

https://doi.org/10.1002/anie.197601231

43. Mehta, G.; Muthusam, M. S. Tetrahedron 2002, 58, 9477. https://doi.org/10.1016/S0040-4020(02)01187-0

44. Mejia-Oneto, J. M.; Padwa, A. Org. Lett. 2006, 8, 3275. https://doi.org/10.1021/ol061137i

45. Mejia-Oneto, J. M.; Padwa, A. Helv. Chim. Acta 2008, 91, 285. https://doi.org/10.1002/hlca.200890034

46. Zhang, H.; France, S.; Mejiá-Oneto, J.M.; Padwa, A. Org. Lett. 2006, 8, 5141. https://doi.org/10.1021/ol062029z

47. Hong, X.; France, S.; Padwa, A. Tetrahedron 2007, 63, 5962. https://doi.org/10.1016/i.tet.2007.01.064 
48. England, D. B.; Padwa, A. Org. Lett. 2007, 9, 3249. https://doi.org/10.1021/ol071173x

49. England, D. B.; Padwa, A. J. Org. Chem. 2008, 73, 2792. https://doi.org/10.1021/jo8001003

50. Choi, Y.; Ishikawa, H.; Velcicky, J.; Elliott, G. I.; Miller, M. M.; Boger, D. L. Org. Lett. 2005, 7, 4539. https://doi.org/10.1021/ol051975x

51. Wilkie, G. D.; Elliott, G. I.; Blagg, B. S. J.; Wolkenberg, S. E.; Soenen, D. R.; Miller, M. M.; Pollack, S.; D. L. Boger, J. Am. Chem. Soc. 2002, 124, 11292.

https://doi.org/10.1021/ja027533n

52. Elliott, G. I.; Fuchs, J. R.; Blagg, B. S. J.; Ishikawa, H.; Yuan, Z.-Q; Tao, H.; D. L. Boger, J. Am. Chem. Soc. 2006, 128, 10589. https://doi.org/10.1021/ja0612549

53. Ishikawa, H.; Elliott, G. I.; Velcicky, J.; Choi, Y.; Boger, D. L. J. Am. Chem. Soc. 2006, 128, 10596. https://doi.org/10.1021/ja061256t

54. Elliott, G. I.; Velcicky, J.; Ishikawa, H.; Li, Y. K.; Boger, D. L. Angew. Chem. Int. Ed. 2006, 45, 620. https://doi.org/10.1002/anie.200503024

55. Ishikawa, H.; Colby, D. A.; Seto, S.; Va, P.; Tam, A.; Kakei, H.; Rayl, T. J.; Hwang, I.; Boger, D. L. J. Am. Chem. Soc. 2009, 131, 4904.

https://doi.org/10.1021/ja809842b

56. Dickman, D. A.; Heathcock, C. H. J. Am. Chem. Soc. 1989, 111, 1528. https://doi.org/10.1021/ja00186a074

57. Heathcock, C. H.; Norman, M. H.; Dickman, D. A. J. Org. Chem. 1990, 55, 798. https://doi.org/10.1021/jo00290a006

58. Barton, D. H. R.; McCombie, S. W. J. Chem. Soc., Perkin Trans. 1 1975, 1, 1574. https://doi.org/10.1039/p19750001574

59. Padwa, A.; Harring, S. R.; Semones, M. A. J. Org. Chem. 1998, 63, 44. https://doi.org/10.1021/jo970847m

60. Padwa, A.; Brodney, M. A.; Marino J. P. Jr.; Sheehan, S. M. J. Org. Chem. 1997, 62, 78. https://doi.org/10.1021/jo960829p

61. Stork, G.; Kretchmer, R. A.; Schlessinger, R. H. J. Am. Chem. Soc. 1968, 90, 1647. https://doi.org/10.1021/ja01008a042

62. Stork, G. Pure Appl. Chem. 1968, 17, 383. https://doi.org/10.1351/pac196817030383

63. Heathcock, C. H.; Kleinman, E.; Binkley, E. S. J. Am. Chem. Soc. 1978, 100, 8036. https://doi.org/10.1021/ja00493a057

64. Mondon, A.; Hansen, K. F.; Boehme, K.; Faro, H. P.; Nestler, H. J.; Vilhuber, H. G.; Böttcher, K. Chem. Ber. 1970, 103, 615.

https://doi.org/10.1002/cber.19701030234

65. Mondon, A.; Seidel, P. R. Chem. Ber. 1971, 104, 2937. https://doi.org/10.1002/cber.19711040935

66. Mondon, A.; Nestler, H. J. Chem. Ber. 1979, 112, 1329. https://doi.org/10.1002/cber.19791120427

67. Sheehan, S. M.; Padwa, A. J. Org. Chem. 1997, 62, 438. https://doi.org/10.1021/jo961690I 
68. Straub, C. S.; Padwa, A. Org. Lett. 1999, 1, 83.

https://doi.org/10.1021/ol9905497

69. Padwa, A.; Sheehan, S. M.; Straub, C. S. J. Org. Chem. 1997, 64, 8648.

https://doi.org/10.1021/jo9911600

70. Mmutlane, E. M.; Harris, J. M.; Padwa, A. J. Org. Chem. 2005, 70, 8055.

https://doi.org/10.1021/jo0511492

71. Raolji, G. B.; Garcon, S.; Greene, A. E.; Kanazawa, A. Angew. Chem. Int. Ed. 2003, 42, 5059 (2003). https://doi.org/10.1002/anie.200352094

72. Jarvis, B. B.; Anderson, C.B. J. Heterocycl. Chem. 1983, 20, 471. https://doi.org/10.1002/ihet.5570200243

73. Majumdar, K. C.; Kundu, A.K.; Chatterjee, P. J. Chem. Res. (S) 1995, 386.

74. Anderson, R. J.; Raolji, G. B.; Kanazawa, A.; Greene, A. E. Org. Lett. 2005, 7, 2989. https://doi.org/10.1021/ol0509641

75. Suga, H.; Hashimoto, Y.; Yasumura, S.; Takezawa, R.; Itoh, K.; Kakehi, A. J. Org. Chem. 2013, 78, 10840. https://doi.org/10.1021/jo401837d

76. Lopchuk, J. M.; Gribble, G. W. Tetrahedron Lett. 2015, 56, 3208. https://doi.org/10.1016/j.tetlet.2014.12.104

77. Huisgen, R.; Gotthardt, H.; Bayer, H.O.; Schaefer, F.C. Angew. Chem., Int. Ed. Engl. 1964, 2, 136. https://doi.org/10.1002/anie.196401361

\section{Author's Biography}

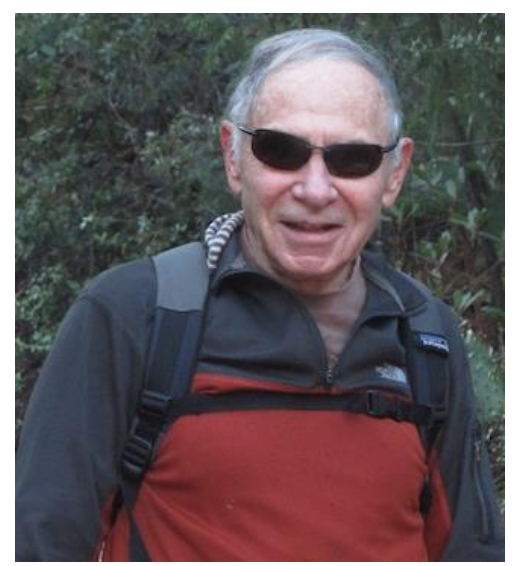

Albert Padwa was born in New York City. He received both his B.A. and Ph.D. degrees from Columbia University. Following an NSF postdoctoral position at the University of Wisconsin, he was appointed as an Assistant Professor of Chemistry at the Ohio State University. He moved to SUNY Buffalo as Associate Professor and was promoted to Professor in 1969. Since 1979, he has been the William Patterson Timmie Professor of Chemistry at Emory University. The research interests of Al Padwa have encompassed heterocyclic chemistry, alkaloid synthesis, tandem organometallic chemistry, and organic photochemistry. Among other awards, he has been the recipient of an Alfred P. Sloan Fellowship, a John S. Guggenheim Fellowship, an Alexander von Humboldt Senior Scientist Award, a Senior Award in Heterocyclic Chemistry from the International Society of Heterocyclic Chemistry and an ACS Arthur C. Cope Scholar Award. He served as the Chairman of the Organic Division of the ACS and as President of the International Society of 
Heterocyclic Chemistry. He is currently one of the Associate Editors for Organic Reactions. His hobbies include climbing tall mountains and building Calder like mobiles. 